\title{
Functional characterization of hydroxyproline-O-galactosyltransferases for Arabidopsis arabinogalactan-protein synthesis
}

\author{
Dasmeet Kaur ${ }^{1,2}$, Michael A. Held ${ }^{1,3}$, Mountain R. Smith² and Allan M. Showalter ${ }^{1,2^{*}}$
}

\begin{abstract}
Background: Arabinogalactan-proteins (AGPs) are structurally complex hydroxyproline-rich cell wall glycoproteins ubiquitous in the plant kingdom. AGPs biosynthesis involves a series of post-translational modifications including the addition of type II arabinogalactans to non-contiguous Hyp residues. To date, eight Hyp-galactosyltransferases (Hyp-GALTs; GALT2-GALT9) belonging to CAZy GT31, are known to catalyze the addition of the first galactose residues to AGP protein backbones and enable subsequent AGP glycosylation. The extent of genetic redundancy, however, remains to be elucidated for the Hyp-GALT gene family.

Results: To examine their gene redundancy and functions, we generated various multiple gene knock-outs, including a triple mutant (galt5 galt8 galt9), two quadruple mutants (galt2 galt5 galt7 galt8, galt2 galt5 galt7 galt9), and one quintuple mutant (galt2 galt5 galt7 galt8 galt9), and comprehensively examined their biochemical and physiological phenotypes. The key findings include: AGP precipitations with $\beta$-Yariv reagent showed that GALT2, GALT5, GALT7, GALT8 and GALT9 act redundantly with respect to AGP glycosylation in cauline and rosette leaves, while the activity of GALT7, GALT8 and GALT9 dominate in the stem, silique and flowers. Monosaccharide composition analysis showed that galactose was decreased in the silique and root AGPs of the Hyp-GALT mutants. TEM analysis of 25789 quintuple mutant stems indicated cell wall defects coincident with the observed developmental and growth impairment in these Hyp-GALT mutants. Correlated with expression patterns, galt2, galt5, galt7, galt8, and galt9 display equal additive effects on insensitivity to $\beta$-Yariv-induced growth inhibition, silique length, plant height, and pollen viability. Interestingly, galt7, galt8, and galt9 contributed more to primary root growth and root tip swelling under salt stress, whereas galt2 and galt5 played more important roles in seed morphology, germination defects and seed set. Pollen defects likely contributed to the reduced seed set in these mutants.

Conclusion: Additive and pleiotropic effects of GALT2, GALT5, GALT7, GALT8 and GALT9 on vegetative and reproductive growth phenotypes were teased apart via generation of different combinations of Hyp-GALT knock-out mutants. Taken together, the generation of higher order Hyp-GALT mutants demonstrate the functional importance of AG polysaccharides decorating the AGPs with respect to various aspects of plant growth and development.
\end{abstract}

\footnotetext{
*Correspondence: showalte@ohio.edu

${ }^{2}$ Department of Environmental \& Plant Biology, Ohio University, Athens,

$\mathrm{OH}$ 45701-2979, USA

Full list of author information is available at the end of the article
}

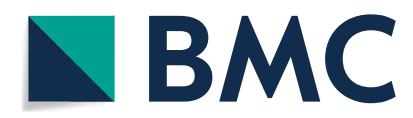

(c) The Author(s) 2021. Open Access This article is licensed under a Creative Commons Attribution 4.0 International License, which permits use, sharing, adaptation, distribution and reproduction in any medium or format, as long as you give appropriate credit to the original author(s) and the source, provide a link to the Creative Commons licence, and indicate if changes were made. The images or other third party material in this article are included in the article's Creative Commons licence, unless indicated otherwise in a credit line to the material. If material is not included in the article's Creative Commons licence and your intended use is not permitted by statutory regulation or exceeds the permitted use, you will need to obtain permission directly from the copyright holder. To view a copy of this licence, visit http://creativecommons.org/licenses/by/4.0/. The Creative Commons Public Domain Dedication waiver (http://creativeco mmons.org/publicdomain/zero/1.0/) applies to the data made available in this article, unless otherwise stated in a credit line to the data. 
Keywords: Arabidopsis, Arabinogalactan-proteins, Hydroxyproline-galactosyltransferase, Reproduction, Pollen, $\beta$-Yariv, Root length, Seed set, Seed germination

\section{Background}

Arabinogalactan-proteins (AGPs) are a complex family of extracellular, hydroxyproline (Hyp)-rich glycoproteins (HRGPs) found throughout the plant kingdom, from aquatic brown and green algae (e.g. Ectocarpus siliculosus) $[1,2]$ to terrestrial angiosperms $[3,4]$. Their complexity is reflected in the multiple AGP subfamilies/core proteins and in the extensive post-translational modifications of these core proteins, which includes hydroxylation of proline residues to form hydroxyproline (Hyp), removal of signal peptide sequences which facilitate extracellular secretion, addition of glycosylphosphatidylinositol (GPI) lipid anchors to allow for attachment of many AGPs on the outer leaflet of the plasma membrane [4-6], and the addition of type II arabinogalactan (AG) polysaccharide side chains catalyzed by diverse set of glycosyltransferases (GTs). AGPs are found at the plasma membrane-cell wall interface, in the cell wall and in plant exudates of most cells, tissues, and organs [7].

Although AGPs account for less than 10\% of the plant cell wall matrix, they are implicated to function in a number of important plant growth and development processes including cell expansion, cell division, programmed cell death, somatic embryogenesis, root formation and development, xylem differentiation, responses to abiotic stress, and hormone signaling [8-13]. AGPs also play important roles in the food, pharmaceutical and mining industries given their remarkable emulsification, adhesion, and lubrication properties. Using bioinformatic analysis, Showalter et al. (2010) identified 85 AGP genes in Arabidopsis and classified them into various subfamilies including classical AGPs, lysine-rich AGPs, AG peptides, fasciclin-like AGPs, and several other chimeric AGPs. Despite the immense importance of AGPs to plants as well as humans, their molecular mechanisms of action with respect to their functions remains elusive.

Given that AGPs generally consist of $1-10 \%(\mathrm{w} / \mathrm{w})$ protein and $~ 90-98 \%(w / w)$ carbohydrate, it is likely that the type II AG sugars of AGPs constitute their functionally interactive surface and are integral to their mechanisms of action $[14,15]$. Typically, type II AGs consist of $\beta-1,3-$ linked galactan main chains substituted with variable lengths of $\beta-1,6$-galactan side chains (up to 100 to 150 sugar residues) which contain $\mathrm{L}$-arabinose along with other sugar residues [16-18].

To date, 20 GTs involved in the synthesis of type II AGs have been identified and characterized [19], including two $\beta$-1,3-galactosyltransferases, namely At1g77810 and
At1g33430 (KNS4), in the GT31 family (http://www.cazy. org/GT31_all.html) [20], two $\beta$-1,6-galactosyltransferases GALT31A and GALT29A in GT31 family [21, 22], three $\beta$-glucuronosyltransferases, GlcAT14A, GlcAT14B, and GlcAT14C, from GT14 family [23, 24], two $\alpha$-fucosyltransferases FUT4 and FUT6, in GT37 [25-27] and one $\beta$-arabinosyl-transferase RAY1 from the GT77 family [28].

In addition to the recently identified Hyp-galactosyltransferase (Hyp-GALT) At1g22015 [29], eight HypGALT genes have been identified and characterized so far. These eight genes reside in two separate clades within the GT31 family in the CAZy database. Of all the GTs involved in the glycosylation of AGPs, the Hyp-GALTs are the most critical as they add the first galactose onto the Hyp residues of the protein backbone and generate the acceptor for subsequent glycosylation events. Five Hyp-GALTs, designated as GALT2-6 by the Showalter lab, were identified by bioinformatic analysis and verified by heterologous expression in Pichia pastoris and Nicotiana benthamiana using an in vitro enzyme assay [30, 31]. By contrast, the other three Hyp-GALTs, designated as HPGT1-3, were identified via affinity chromatography with an AGP peptide followed by protein sequencing and heterologous expression coupled with an in vitro enzyme assay [32]. For simplicity, these eight Hyp-GALTs will be referred to as GALT2-9, such that HPGT1-3 are renamed as GALT7-9. One Hyp-GALT clade in GT31 consists of GALT2 (At4g21060), GALT3 (At3g06440), GALT4 (At1g27120), GALT5 (At1g74800), and GALT6 (At5g62620), and these genes encode proteins having a GALT domain (pfam01762) as well as a GALECTIN (pfam00337) domain. A second Hyp-GALT clade in GT31 consists of GALT7/HPGT1 (At5g53340), GALT8/ HPGT2 (At4g32120) and GALT9/HPGT3 (At2g25300), and these genes encode proteins that only have a GALT domain and lack a GALECTIN domain [19, 32, 33].

Single genetic knock-out mutants for these eight HypGALTs demonstrated subtle or no discernable plant phenotypes compared to wild-type (WT) plants. The galt2 galt5 double mutant, however, displayed pleiotropic effects including impaired root growth, root tip swelling in response to salt stress and a reduction in seed coat mucilage [34]. Whereas the hpgt1 hpgt2 hpgt3 triple mutant exhibited reductions in plant height, leaf size, seed set, silique length as well as an increase in root length. Moreover, Zhang et al. (2021) reported gene redundancy of a GT31 galactosyl-transferases belonging 
to a single clade (with both GALT and GALECTIN domains) by generating a triple mutant galt3 galt4 galt6 and quintuple mutant galt2 galt3 galt4 galt5 galt6 using CRISPR/Cas9 gene editing/multiplexing approach, which exhibited reduced overall growth, impaired root growth, abnormal pollen, and reduced seed set with shorter siliques [35].

Given the complexity in understanding the roles of multiple genes belonging to two subfamilies (clades), we hypothesized that knocking out multiple HypGALTs in different combinations will allow us to examine the extent of gene redundancy in two Hyp-GALT clades with structural domain differences and to elucidate the biological contributions of these two different clades on vegetative and reproductive organs by extensive phenotypic analysis. Here, we report the generation and extensive characterization of multiple HypGALT (T-DNA) gene knockout mutants, including a triple mutant (galt5 galt8 galt9), two quadruple mutants (galt2 galt5 galt7 galt8, galt2 galt5 galt7 galt9) and one quintuple mutant (galt2 galt5 galt7 galt8 galt9) and discuss the new insights with respect to Hyp-GALT partial genetic redundancy, AGP biosynthesis and AGP functions.

\section{Results}

\section{Expression profiles of eight Hyp-GALTs in the GT31 family}

Expression of the eight Hyp-GALTs genes was examined in various vegetative and floral organs/tissues using publicly available RNA-seq data sets with Araport (Supplemental Fig. 1). This in silico analysis indicated mostly overlapping tissue expression patterns for the eight genes throughout the plant except pollen which showed unique expression pattern, corroborating previous studies based on microarray and quantitative RT-PCR data (Basu et al., 2015; Ogawa-Ohnishi and Matsubayashi, 2015; Basu et al., 2016). All the Hyp-GALTs genes were expressed in multiple plant organs/tissues including stem/aerial, carpel, inflorescence, leaf, pollen, root, seedling, root and shoot apical meristem. Among the eight genes, GALT7 generally displayed the highest expression levels, particularly in inflorescence and root tissues.

In addition, transcriptomic analysis data of laser-capture micro-dissected seeds as depicted in the BAR eFP browser [36] showed high but distinct expression patterns for the Hyp-GALT genes during various stages of seed development (Supplemental Fig. 2). GALT2, GALT3, GALT5 and GALT8 were highly expressed in the seed coat at the pre-globular and globular stages of seed development, while GALT4, GALT7, GALT8 and GALT9 were highly expressed in the micropylar endosperm. These expression patterns during seed development pointed towards a possibility of germination and seed coat defects in Hyp-GALT mutants.

\section{Generation of higher-order Hyp-GALT knock out mutants} T-DNA insertion alleles GALT2, GALT5 [30] as well as GALT7, GALT8 and GALT9 [32] were used to generate multiple higher-order mutants (Fig. 1A and Supplemental Table 1). All the single alleles were reported to be T-DNA insertions in the introns, exons or UTRs: galt2-2, galt8 (hpgt2-1) and galt9 (hpgt3-1) had a T-DNA insertion in exon seven, four and one respectively, galt5-1 had T-DNA insertion in 5'UTR whereas galt7 (hpgt1-1) had a T-DNA insertion in intron six. galt2 galt5 double mutant and the galt7 galt8 galt9 (hpgt1 hpgt2 hpgt3) triple mutant, which were reported in previous studies [30, 32], were crossed to generate a line heterozygous for all these Hyp-GALT genes, namely galt2 galt5 galt7 galt 8 galt9. This line was self-pollinated and the resulting F2 and F3 plants were subjected to PCR genotyping to isolate various triple, quadruple, and quintuple homozygous mutants (Fig. 1B). All five genes used in this study are located on different chromosomes or are far apart on the same chromosome in the Arabidopsis genome in one case. GALT2, GALT5, GALT7, GALT8, and GALT9 are located on chromosome IV, I, V, IV and II, respectively. The GALT2 and GALT8 genes located $4.27 \mathrm{Mb}$ apart on the long arm of the chromosome IV according to The National Center for Biotechnology Information [37].

The resulting mutants obtained from the F2 and F3 screening used in this study were galt 5 galt 8 galt 9 , galt 2 galt5 galt7 galt8, galt2 galt5 galt7 galt 9 and galt 2 galt 5 galt7 galt8 galt9 (see Key in Fig. 1D) along with WT (Col0), galt2 galt5 and galt7 galt8 galt9 as controls. Figure 1C provides an example of genotype conformation for the quintuple mutant.

\section{Relative expression profiles of the Hyp-GALT genes in higher-order mutants}

Quantitative reverse transcription (qRT-PCR) was performed to assess the expression of the five Hyp-GALT genes: GALT2, GALT5, GALT7, GALT8 and GALT9 genes from inflorescences collected from the plants grown on soil for $40 \mathrm{~d}$ (Fig. 2) which is in good agreement with qRT-PCR and RT-PCR of single allelic mutants and the 25 double mutant in previous studies [30, 31, 34]. In our study, the relative expression of the HypGALT genes in the various mutants confirmed the near absence of mutant allele expression in all higher-order mutants (marked with asterisks) along with a concomitant increase or similar amount of expression of the normal alleles (with no mutation). Multiple mutations in the Hyp-GALTs generally lead to the upregulation of normal 


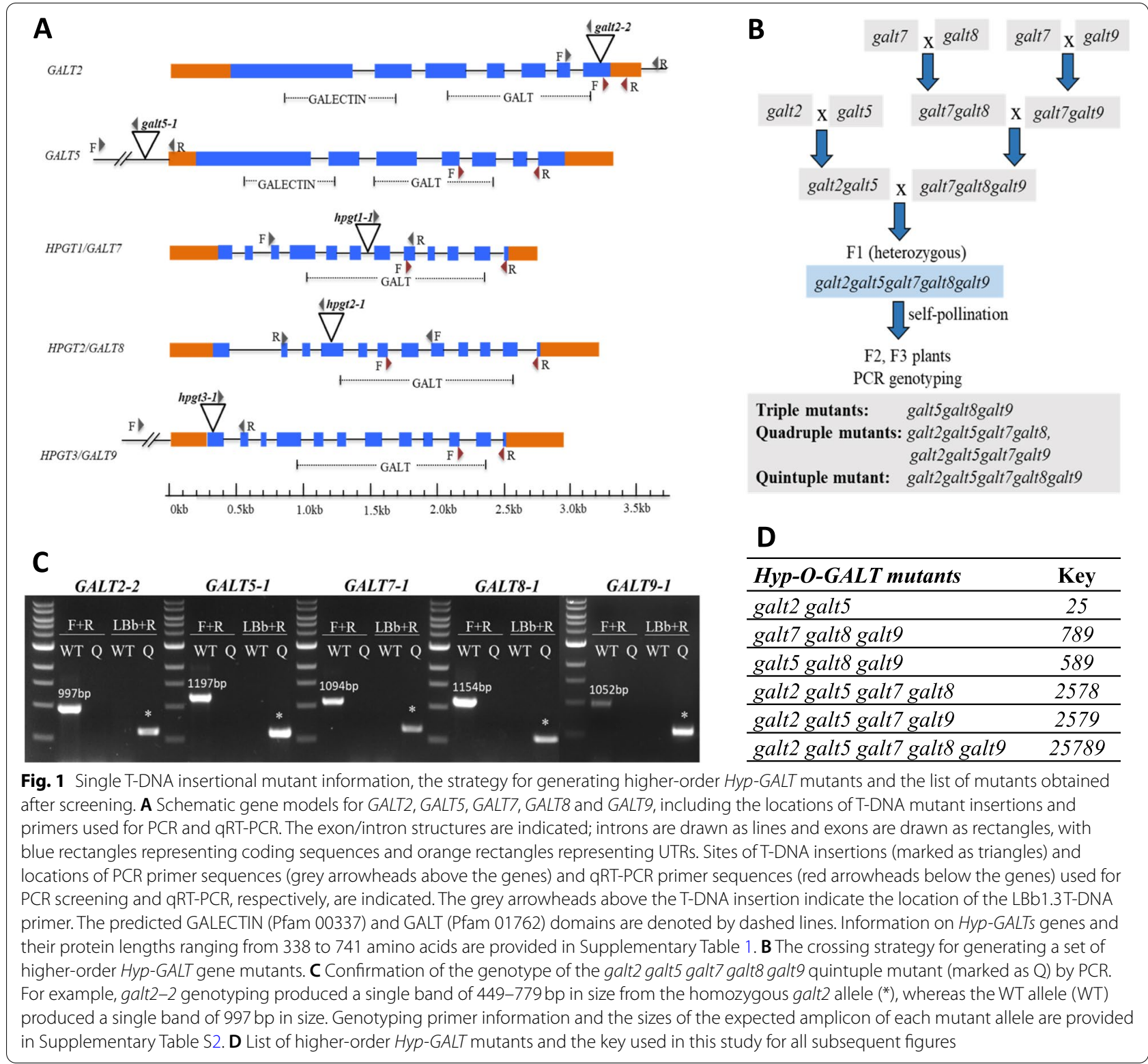

Hyp-GALTs for compensation. For example, GALT8 in 2579 was upregulated up to 2.3 -fold in comparison to relative gene expression of 1 in WT.

Hyp-GALT mutants have reduced $\beta$-Yariv-precipitable AGPs To investigate the effect of GALT mutations on glycosylation of AGPs, we performed quantification of $\beta$-GalYariv precipitable AGPs. $\beta$-Gal-Yariv, a specific binding agent to detect, quantify, and purify AGPs via binding with $\beta$-1,3-galactan chains [38]. AGPs were precipitated and quantified from rosette leaf, cauline leaf, stem, roots, siliques, and flowers of Hyp-GALT mutant plants.
Overall, significant reductions in $\beta$-Gal-Yariv precipitable AGPs were observed in all organs examined for the mutants (Fig. 3), which is in agreement with the expression patterns of the Hyp-GALTs in virtually all plant organs examined. The 25 double mutant produced a $10-42 \%$ decrease in precipitable AGP content compared to the WT in various plant organs. In contrast, 789 displayed a much higher reduction in $\beta$-Gal-Yariv precipitable AGPs in flowers, roots, and rosette leaves with an average of 69,59 and $75 \%$ reductions respectively compared with WT. The 789 triple mutant also displayed a much greater reduction in AGP content in comparison to the other triple mutant 589 . 

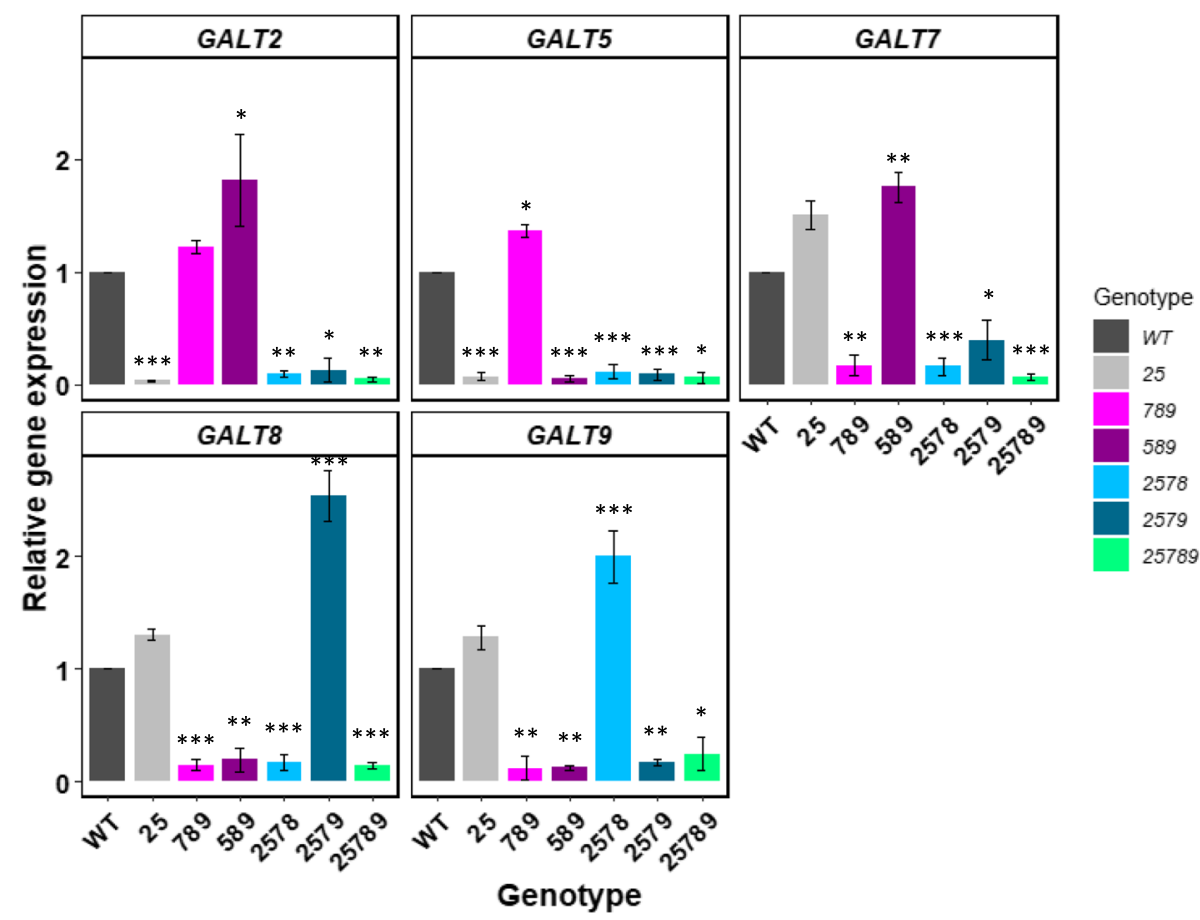

Fig. 2 Relative expression profile of the five Hyp-GALT genes in higher-order Hyp-GALT mutants compared to WT determined via qRT-PCR. Total RNA was extracted from inflorescence samples collected from the various Hyp-GALT mutant plants at 40 days after germination (DAG). Expression levels were normalized to the ACT2 gene (mean \pm SE of three biological replicates). In addition, expression levels of each gene in WT plants were set to one. An analysis of variance (ANOVA) on these mutants yielded significant variation among conditions. A post hoc Tukey test was applied to see which groups were significantly different from wild-type (Col-0). ${ }^{*} P<.05,{ }^{* *} P<0.005$, ${ }^{* *} P<0.001$

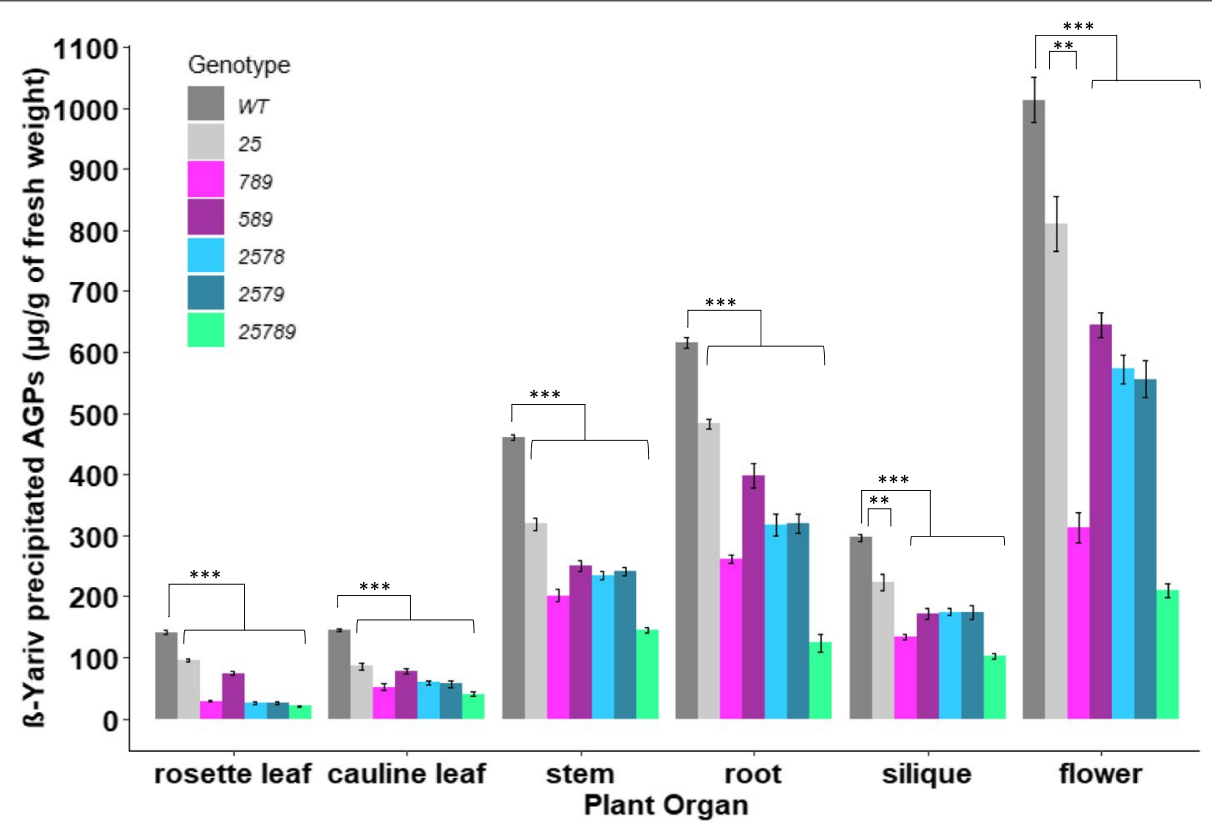

Fig. 3 Amount of $\beta$-Gal-Yariv precipitated AGPs in WT and higher-order Hyp-GALT mutants in different organs. All the higher-order mutants showed significant reductions of AGP content in stems, siliques, rosette leaves and cauline leaves. The 25789 quintuple mutants showed the greatest reduction of AGP content in both rosette leaves and stems followed by other double, triple and, quadruple mutants. The asterisks indicate significantly reduced $\beta$-Gal-Yariv precipitated AGPs in comparison to the WT controls according to a Student's t test $\left(* *, P<0.01,{ }^{* * *} P<0.001 ; n=4\right)$ 
The quadruple mutants 2578 and 2579 exhibited nearly similar amounts of reductions of precipitable AGPs such that stem, silique and flowers ranged between 45 and $50 \%$, while cauline leaves and rosette leaves reductions ranged between 60 and $75 \%$. These quadruple mutants 2578 and 2579 did not exhibit AGP reductions as high as in the stems, siliques and flowers of 789 . Introducing mutation of two genes galt2 galt5 in place of one gene galt7 in combination with galt8 galt9 did not produce as much of a reduction in precipitated AGPs as in 789, indicating that 789 caused a greater effect on AGPs than other GALTs in stem, roots, silique and flower. These results are corroborated by transcript levels depicted by in silico gene expression profiles of Hyp-GALTs among different organs where GALT2 and GALT5 have lower transcript levels than GALT7 in carpel and inflorescence (Supplemental Fig. 1). However, the cauline and rosette leaves of 789, 2578, 2579 had similar levels of reduction in precipitable AGPs.

Clearly, the 25789 quintuple mutant exhibited the highest reductions in AGP precipitations such that flower, root and rosette leaf exhibited about an $80 \%$ decrease whereas other organs (stem, silique and cauline leaf) showed an $\sim 70 \%$ reduction in precipitable AGPs.

\section{Monosaccharide composition analysis of the Hyp-GALT mutants}

To investigate the effect of introducing Hyp-GALT mutations on AGP sugar compositions, $\beta$-Gal-Yariv purified
AGPs were extracted from silique and root tissues of Hyp-GALT mutants and were subjected to monosaccharide composition analysis (Fig. 4). The data showed that AGPs from all organs were mainly composed of Gal and Ara residues in approximately 1.5-2:1 molar ratio. AGPs obtained from the roots and siliques generally demonstrated a decrease in Gal content in the Hyp-GALT mutants compared to the WT.

The 25789 mutant siliques displayed a maximum reduction in Gal content of $12.5 \%$ in siliques (Fig. $4 \mathrm{~A}$ ) and $18.6 \%$ in roots (Fig. 4B). For silique tissues, 25789 was followed by less severe $\mathrm{Gal}$ content reductions in the three lesser mutants (789, 2578 and 2579); while 589 and 25 showed Gal content similar to WT. In root tissues, 25789 was followed by smaller reductions in Gal content in four mutants (25, 789, 2578 and 2579); while 589 showed Gal content similar to WT. Unlike roots, the Rha in siliques also decreased significantly in higher-order mutants specifically in 25789. A concomitant increase in the percentages of other sugars like Xyl and/or Man were observed in root and silique with subtle variations, which is likely a result of expressing the data as molar percentages.

Interestingly, the calcium content bound to extracted AGPs displayed a significant reduction (12-31\%) in the silique, flower, stem and root tissues of the quintuple mutant 25789 only but not in any other Hyp-GALT mutant compared to the WT (Fig. 5).
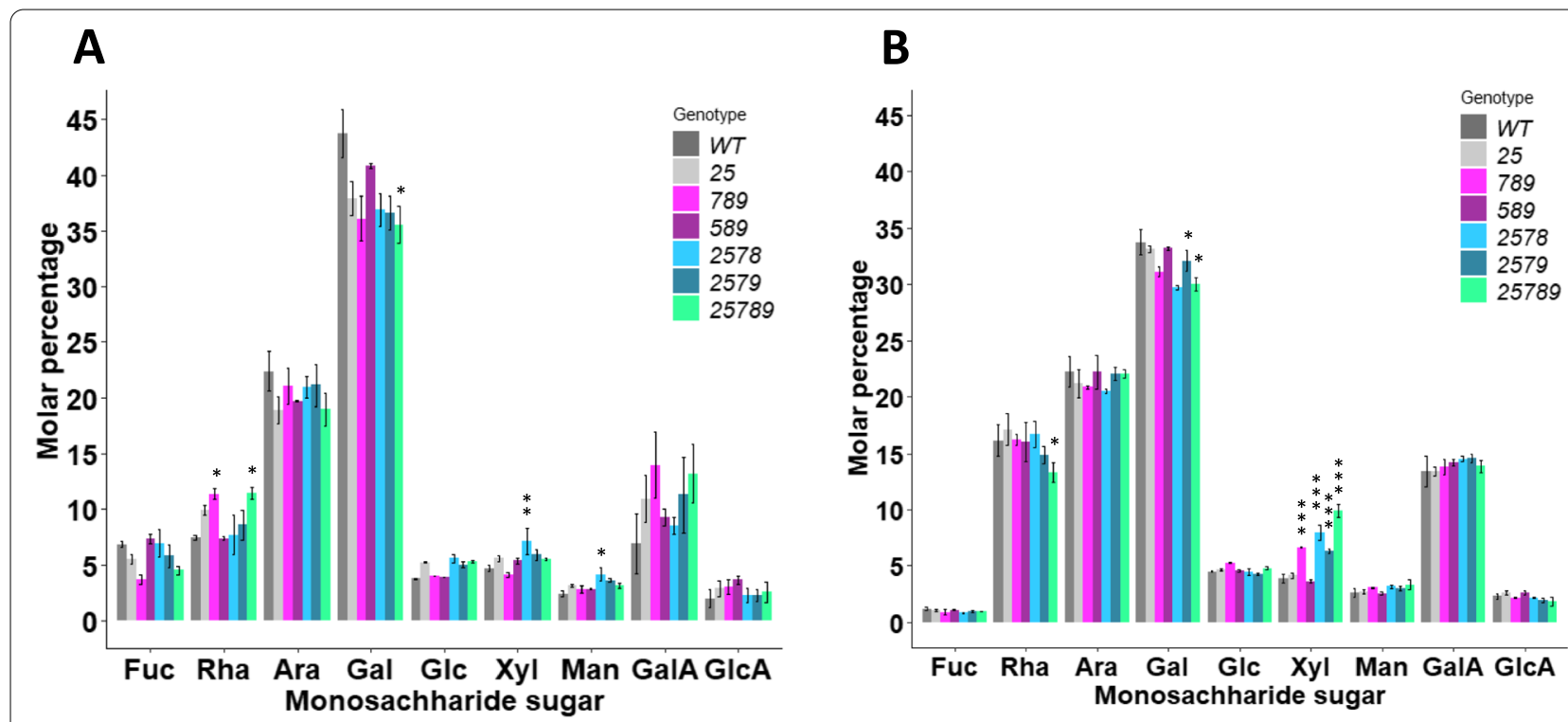

Fig. 4 Monosaccharide composition analysis of AGPs isolated from (A) silique and (B) roots of Hyp-GALT mutants. AGPs were extracted and purified from siliques and roots of Hyp-GALT mutants and WT plants $(n=3)$. An analysis of variance (ANOVA) on these mutants yielded significant variation among genotypes. A post hoc Tukey test was applied to see which groups were significantly different from $\mathrm{WT}(\mathrm{Col}-0)$. ${ }^{*} P<.05$, ${ }^{* *} P<0.005$, ${ }^{* * *} P<0.001$ 


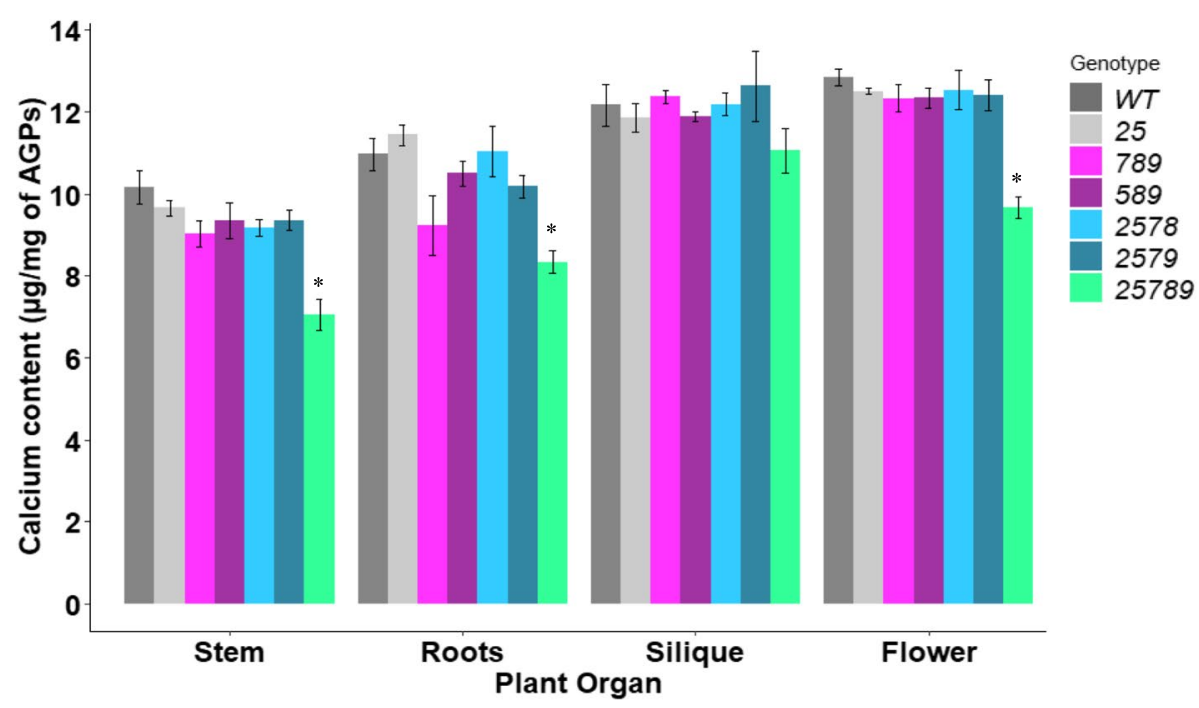

Fig. 5 Calcium binding ability of AGPs of Hyp-GALT mutant stem, roots, siliques, and flowers. AGPs were extracted and purified from stem, flower, silique and roots of Hyp-GALT mutants and WT plants $(n=3)$. Student's t-test was employed to calculate significant differences from respective WT samples of each organ. $\left({ }^{*} P<0.05,{ }^{* *} P<0.01,{ }^{* * *} P<0.001\right)$

\section{Hyp-GALT mutants exhibit germination defects}

A significant delay in germination of the quintuple 25789 was observed under normal conditions in post-harvested (>6-8 months) seeds. At $36 \mathrm{~h}$, only $22 \%$ germination was seen in the quintuple 25789 mutant, followed by quadruples, 2578 and 2579 demonstrating 30-33\% germination rates in comparison to WT, while 25, 589 and 789 exhibited maximum germination rates (40-43\%) similar to WT. By $48 \mathrm{~h}$, all genotypes germinated to their maximum germination percentages. At $48 \mathrm{~h}$, the quintuple 25789 mutant showed a maximum germination rate of $54 \%$ whereas quadruples 2578 and 2579 displayed a maximum germination rate of $80-83 \%$ in comparison to WT, 25,589 and 789 , which attained $95-98 \%$ germination (Fig. 6A and B).

Furthermore, the radicle length was measured at $48 \mathrm{~h}$ after sowing. The 789 mutant showed a slightly negative effect on radicle length growth, though statistically non-significant. Interestingly, the quintuple mutant 25789 showed a significantly smaller radicle length $(41 \%$ smaller radicle length) compared to the WT and all other Hyp-GALT mutants (Fig. 6C). In addition, for the postharvested ( $>6-8$ months) seeds, germination percentages reduced in quadruple $(2578,2579)$ by 12 and $15 \%$ which were not statistically significant though. The quintuple (25789) mutants showed significant decrease of $45 \%$ in germination percentage (Fig. 6D and E) in comparison to WT. For the WT, 25, 789, and 589, the germination percentage ranged between 94 and $99 \%$.

\section{Hyp-GALT mutants exhibit stunted plant growth when grown on soil and plates}

To investigate the effect of Hyp-GALT mutations on plant vegetative growth, mutants and WT were grown on $1 / 2$ MS media. The higher-order Hyp-GALT mutants exhibited pronounced pleiotropic morphological alterations in vegetative growth and bolting (Figs. 7 and 8) whereas single Hyp-GALT mutants showed no obvious phenotypes in previous studies [31, 32, 34]. The 789 triple mutant, as well as the 2578 and 2579 quadruple mutants showed significant reductions in plant height by $14-25 \%$, while the quintuple mutant 25789 demonstrated $40 \%$ reduction in plant height compared to WT at 50 DAG (Fig. 7A and D). The 589 triple and 25 double mutants, however, did not show any significant effect with respect to this growth phenotype.

The days to flowering was also delayed significantly in the 789,2578 and 2579 mutants by $3-5 \mathrm{~d}$ and in the quintuple mutant 25789 by $10-11 \mathrm{~d}$ (Fig. 7A and C). The higher-order Hyp-GALT mutants also demonstrated retarded growth of rosette leaves as seen in Fig. 7B; this is evident in $789,2578,2579$, and is the most severe in 25789 (Supplemental Fig. 3).

The 2578 and 2579 quadruple mutants showed no significant primary root growth. The 789 mutants showed significant reduction (21\%) in primary root growth while the 25789 quintuple mutants displayed the most retarded primary root growth (38\%) (Fig. 8A and B). In contrast, the root hair density and root-hair length were not affected much (Fig. 8C and Supplemental Fig. 4) in these mutants with the exception of the 25789 mutant which 

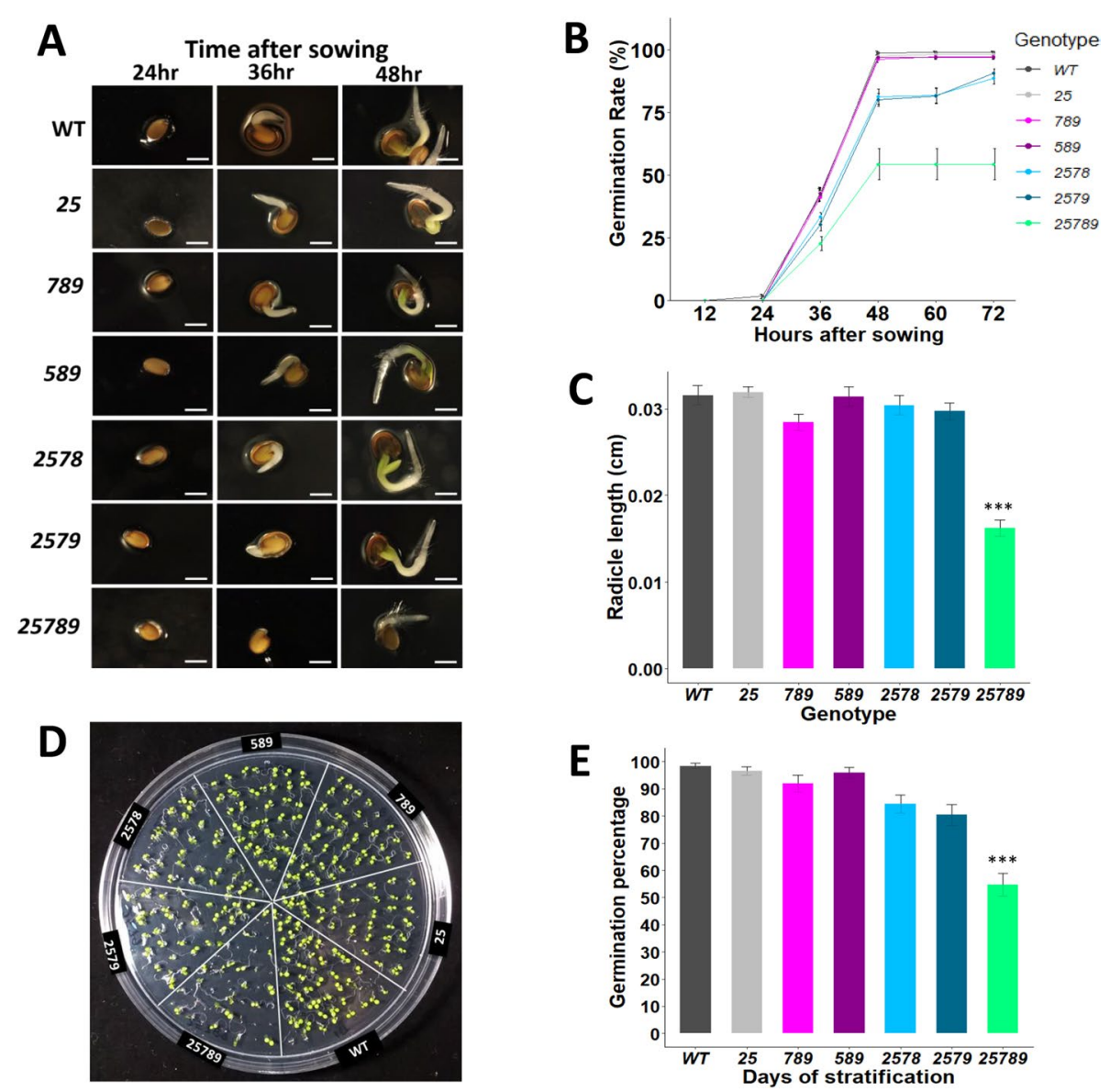

Fig. 6 Germination rates and percentages of Hyp-GALT higher-order mutants. A Representative images for the germination rate as indicated by the emergence of the radicle from the seeds of the WT and higher-order Hyp-GALT mutants on $1 / 2$ MS media. In comparison to WT seeds, the mutants displayed delayed germination. Seeds of all the genotypes were sterilized, plated on $1 / 2$ MS media, and then stratified for $3 \mathrm{~d}$. Images were taken at 12, 24, 36, 48, 60 and $72 \mathrm{~h}$ after sowing. Scale bar $=0.5 \mathrm{~mm}$. B Germination rates were measured in three independent experiments $(n=96)$. Radicle length was measured by Motic Image version 3.2 at $48 \mathrm{~h}$ and quantified in $(\mathbf{C})$. For radicle length, 35 germinated seeds from each genotype were measured with three biological experimental replicates. An analysis of variance (ANOVA) on these mutants yielded significant variation in radicle lengths. A post hoc Tukey test was applied to see which groups were significantly different from WT $\left(\right.$ Col-0). ${ }^{*} P<.05$, ${ }^{* *} P<0.005$. D Germination percentages of the higher-order Hyp-GALT mutants. Photos of the seedlings of Hyp-GALT mutants and WT (WT) at 4 DAG were taken, and germination percentages were determined and compared to WT (control) plants under normal conditions $(n=144)$ in four independent experiments (E). An analysis of variance (ANOVA) on these mutants yielded significant variation among genotypes. A post hoc Tukey test was applied to see which groups were significantly different from WT (Col-0). ${ }^{*} P<.05,{ }^{* *} P<0.005,{ }^{* * *} P<0.001$. DAG, days after germination

showed a small increase in root hair density and a small decrease in root hair length.

The higher-order Hyp-GALT mutants showed much more pronounced salt hypersensitivity response in form of root tip swelling compared to previously reported in single and double Hyp-GALT mutants [34]. All of the higher-order Hyp-GALT mutants displayed root tip swelling and decreased root elongation compared to WT plants; however, 589, 2578, 2579 showed the less severe root growth defects in comparison to 789 and 25789 (Fig. 8D and Supplemental Fig. 5). $\beta$-Yariv reagent is known to inhibit root growth by binding to AGPs $[8,35,39]$. Seedlings of all genotypes were grown in the presence of $\beta$-Gal-Yariv reagent such that WT seedlings displayed reduced root growth as expected (Fig. 8E). In contrast, all Hyp-GALT mutants showed a $\beta$-Yariv insensitive root growth phenotype; 789 and 25789 displayed the highest $\beta$-Yariv insensitivity with respect to root growth (Fig. 8F) as quantified $7 \mathrm{~d}$ and $14 \mathrm{~d}$ after transfer to $\beta$-Yariv.

Altered cell wall structure in $\mathbf{2 5 7 8 9}$ quintuple mutant stems Since the 25789 mutants exhibited stunted seedling growth and shortened inflorescence stems (Fig. 7), 


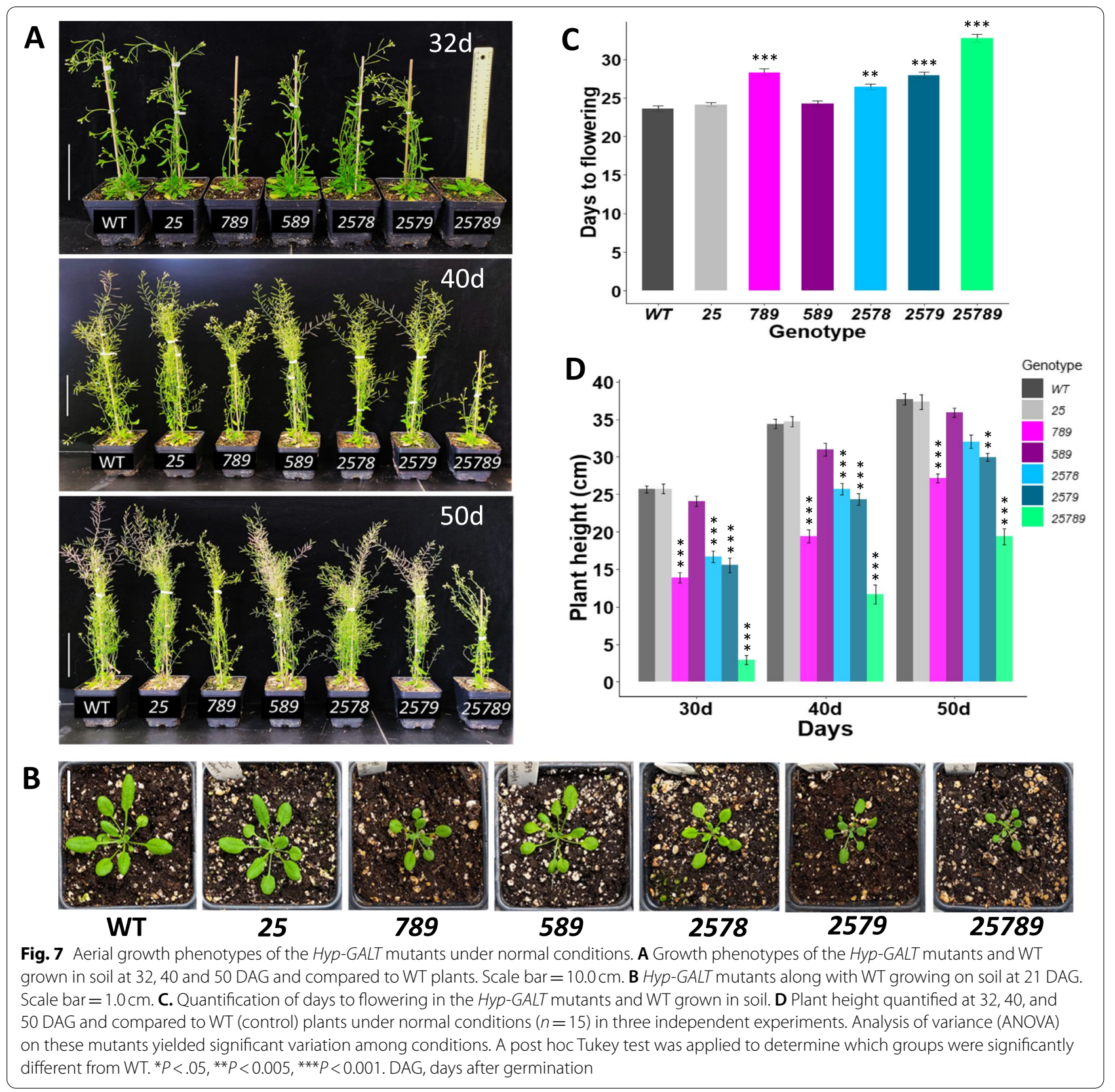

transverse sections of fresh tissue from the base of the 8-week-old inflorescence stem were stained with toluidine blue for cell wall polysaccharides, to visualize differences in primary and/or secondary cell wall morphology (Fig. 9). The results revealed that 25789 mutant stems (Fig. 9A, B) have smaller vascular bundles (Fig. 9C, D) with reduced thickness of fiber cells, xylem fibers, vessels and interfascicular fibers stems (Fig. 9F, H) compared to the WT (Fig. 9E, G). Moreover, transmission electron microscope (TEM) analysis of cross sections confirmed thinner secondary cell walls in the vessels, vascular fibers and interfascicular fibers of the 25789 mutants (Fig. 9H, L) relative to WT (Fig. 9G, K).

Hyp-GALT mutants display reduced seed set and abnormal seed morphology

The higher-order Hyp-GALT mutants displayed a significant reduction in total siliques per plant in the 25789 mutants $(25 \%)$ in comparison to WT unlike the other 


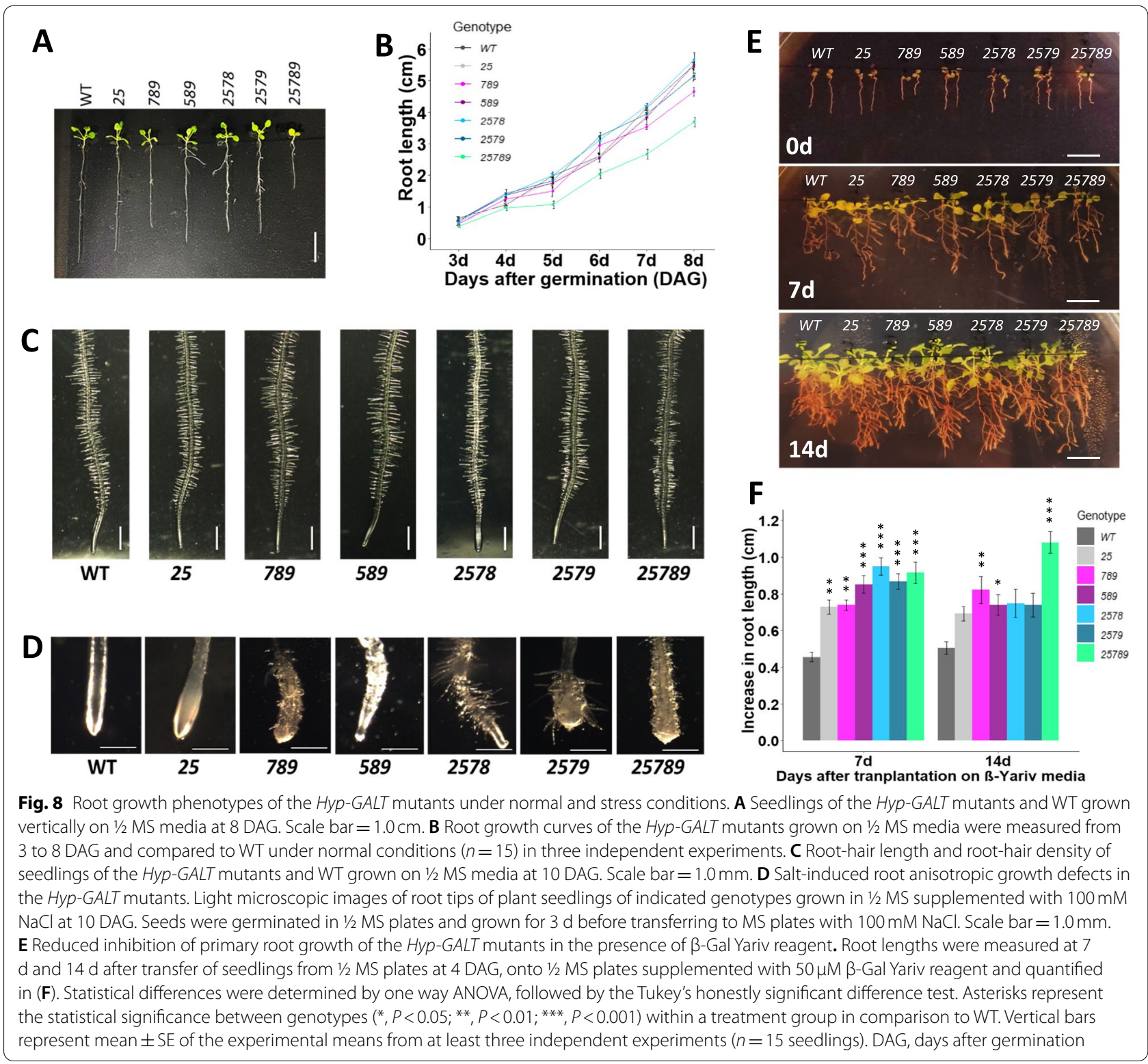

mutants (Fig. 10C). The 25789 mutant also demonstrated most dramatic reduction in seed set $(\sim 70 \%)$ compared to $14-15 \%$ reductions in the average seed set for the 789 , 2578, 2579 mutants; (Fig. 10A, B and E). The analysis of basal (oldest) fifteen siliques on the main inflorescence stem also showed the reduction in seed set of 25789 mutant compared to the WT (Fig. 10A and S6). The average silique length was also reduced in the higher-order Hyp-GALT mutants (Fig. 10A, B and D). The average silique length was affected more for 789 (22\% reduction) than both 2578 and 2579 , which showed $11 \%$ reductions; however, 25789 exhibited a 60\% reduction (Fig. 10E and Supplemental Fig. 7).
SEM seed morphology analysis revealed that the quintuple mutant exhibited altered seed shape and disfigured remnants of columellae. No such discernable differences were found in other mutant seeds (Fig. 11A and B). To examine the involvement of AGPs and the Hyp-GALTs in modifying seed coat mucilage, ruthenium red staining which stains acidic biopolymers such as pectin, and calcofluor staining, which stains cellulose as well as $\beta$-glucans, were done with the Hyp-GALT mutants (Fig. $11 \mathrm{C}$ and D). All Hyp-GALT mutants displayed reduced cellulose ray staining and reduced pectin staining in the mucilage adhering to the seeds compared to the WT with 25789 displaying the 

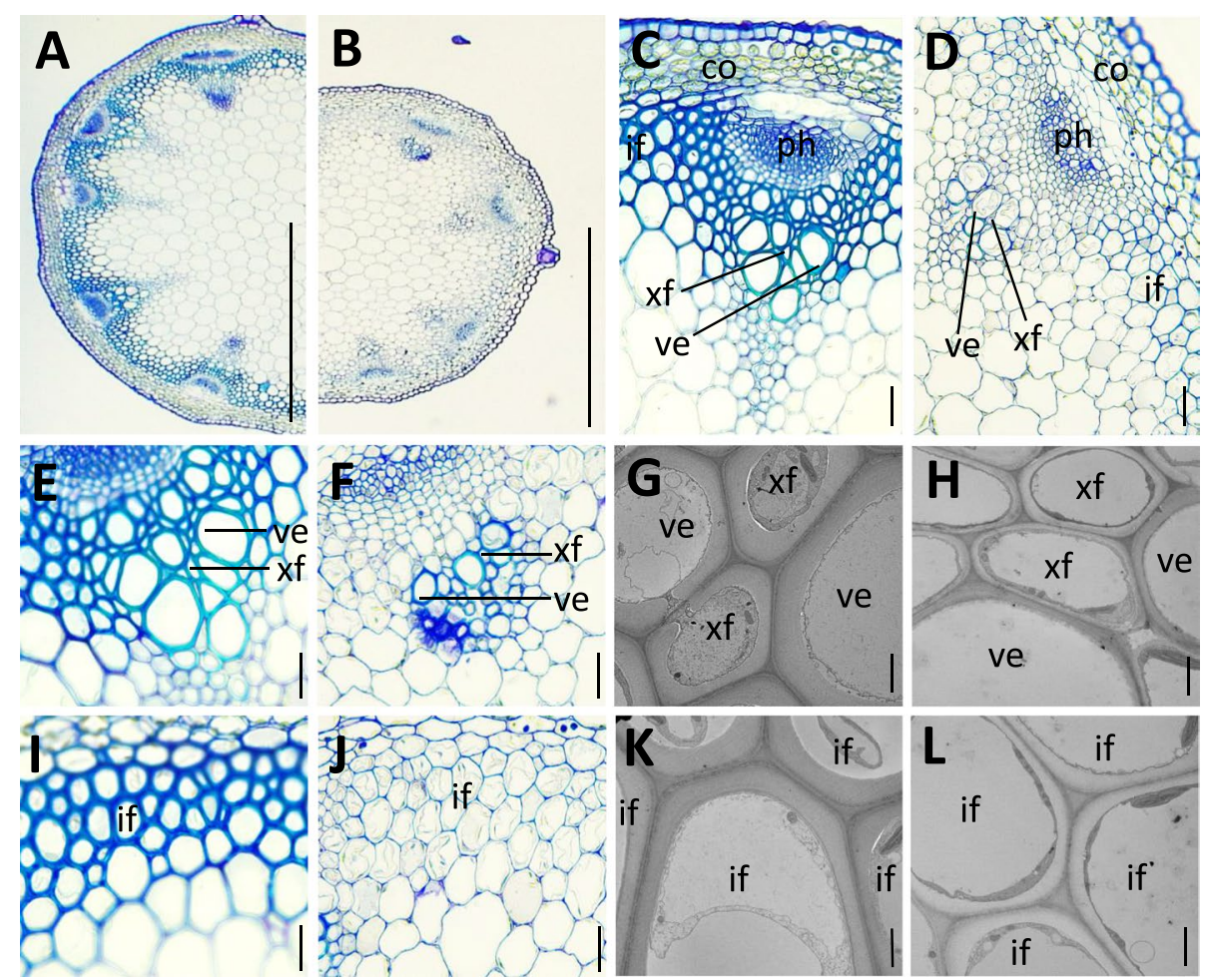

Fig. 9 Altered stem cell wall architecture in 25789 mutant. A and $\mathbf{B}$ Cross section of the WT (A) and 25789 mutant stem (B). C. and D. Cross section of the vascular bundle region of WT (C) and 25789 mutant (D). E. and F. Cross sections of vascular bundles of WT (E) and 25789 mutant (F). I. and J. Cross section of interfascicular region of WT (I) and 25789 mutant (J). $\mathbf{G}$ and $\mathbf{H}$ Transmission electron micrographs of xylem cells of WT (G) and 25789 mutant stem (H). $\mathbf{K}$ and $\mathbf{L}$. Transmission electron micrographs of interfascicular fiber cells of WT (K) and 25789 mutant stem. co: cortex, if: interfascicular fiber, ph: phloem, ve: vessel, xf: xylary fiber. Scale bars $=500 \mu \mathrm{m}$ in (A, B), $20 \mu \mathrm{m}$ in (C, D, E, F, I and J), $2 \mu \mathrm{m}$ in $(\mathbf{G}, \mathbf{H}, \mathbf{K}, \mathbf{L})$

strongest reduction in seed mucilage pectin and cellulose staining. To examine and quantify the alterations in the outer, non-adherent mucilage versus the adherent mucilage, sequential extraction of seeds with ammonium oxalate and $0.2 \mathrm{~N} \mathrm{NaOH}$ (for extraction of soluble and weakly attached pectins) followed by $2 \mathrm{~N} \mathrm{NaOH}$ (for extraction of strongly linked pectins and cross-linking glycans/hemicelluloses) was performed [40] (Supplemental Table 4). The higher-order Hyp-GALT mutant seeds had a significant increase in the total sugar present in the ammonium oxalate and $0.2 \mathrm{~N} \mathrm{NaOH}$ extracts with a concomitant decrease in the adherent mucilage compared to WT seeds. These observations corroborate the results of ruthenium red staining which also suggested a decrease in adherent mucilage of the higherorder Hyp-GALT mutants.

\section{Hyp-GALT mutants display anther and pollen defects}

Hyp-GALT genes are highly expressed in the inflorescence and in the pollen (Supplemental Fig. 1). Moreover, as previous studies on single Hyp-GALT mutants also demonstrated pollen tube growth defects [31], we microscopically examined our higher order Hyp-GALT mutants for phenotypic differences in male reproductive tissues. As shown in the Supplemental Fig. 8, the arrangement of floral reproductive organs appeared indistinguishable from the WT plants, although the overall flower size was smaller in the 25789 mutant.

In vitro pollen germination was affected only for 25789 , which showed $50 \%$ germination in comparison to $77 \%$ germination in the WT (Fig. 12A and C). For pollen tube lengths, an $8-10 \%$ reduction was observed for mutants, 789,2578 , and 2579, whereas 25789 exhibited a $44 \%$ reduction compared to WT (Fig. 12DD). A defective pollen phenotype was also observed in the Hyp-GALT mutants (Figs. $12 \mathrm{G}$ and 13). Around $10-12 \%$ of defective pollen was observed in the 789 , 2578, and 2579 mutants, whereas the 25789 mutant exhibited $20 \%$ defective pollen. Further, SEM analysis revealed defects in 25789 with abnormal exine structure with smaller lacunae and abnormal reticulate structure (Fig. 13).

The 789, 589, 2578, 2579, and 25789 mutants also displayed reduced inhibition of pollen tube growth 


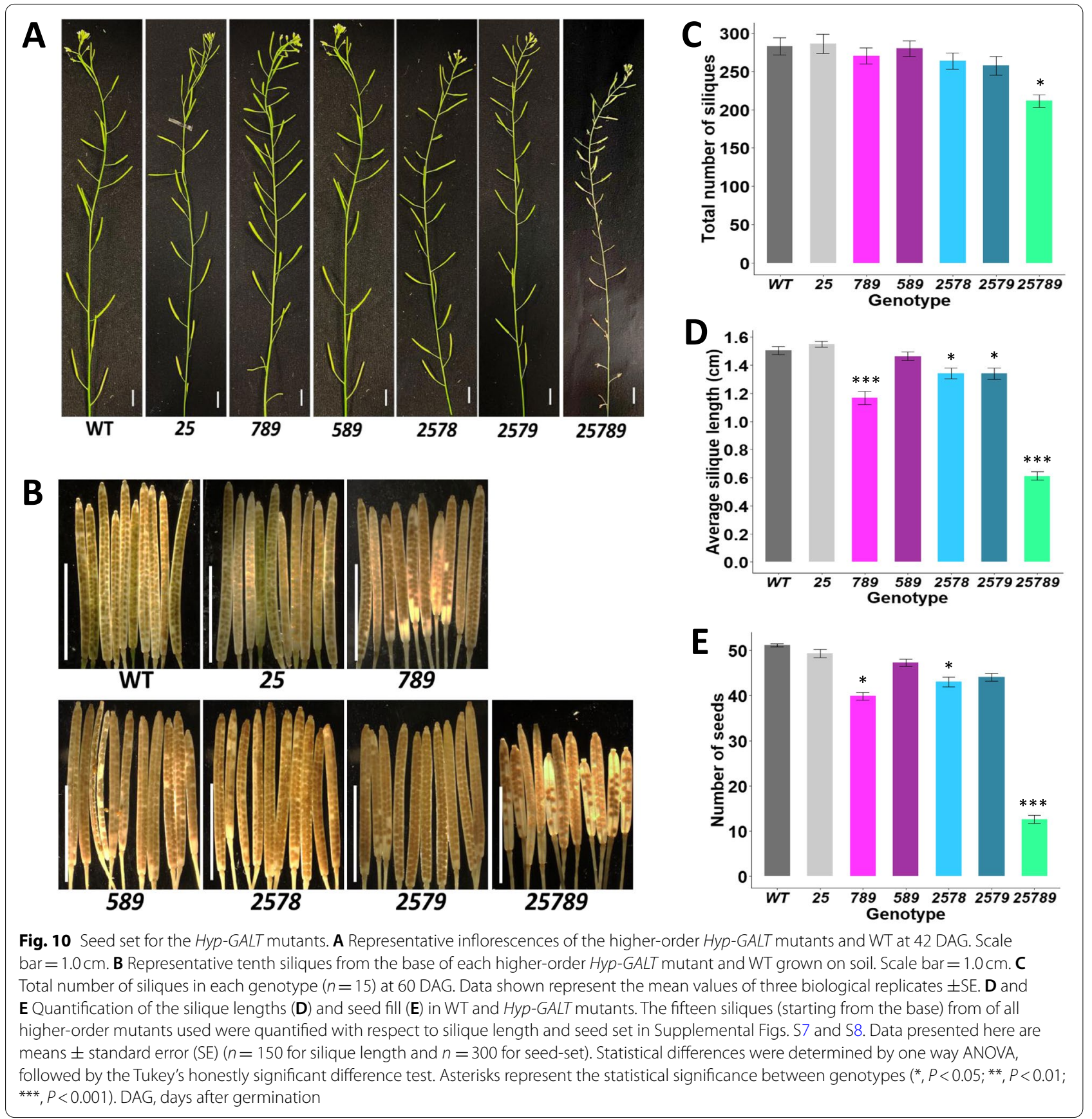

in response to $\beta$-Gal-Yariv reagent compared to WT (Fig. 12B, E and F); maximum pollen tube elongation was observed in 25789 which was $44 \%$ longer than WT.

\section{Discussion}

Gene structure, expression and functions of two small Hyp-GALT multigene families

Eight Hyp-GALT genes belonging to two small multigene families (clades) in the CAZy GT31 family are known to add galactose onto the peptidyl Hyp residues in AGP core proteins This addition represents the first committed step in AG polysaccharide addition and an ideal control point to study the importance and contributions of Hyp-linked type-II AG chains to the biological functions of AGPs. In addition to the conserved GALT domain in all Hyp-GALTs, the GALT2-6 family members in clade $B$ (subclades $\mathrm{V}$ and VI) contain a GALECTIN domain, which is absent in the GALT7-9 family members in clade 


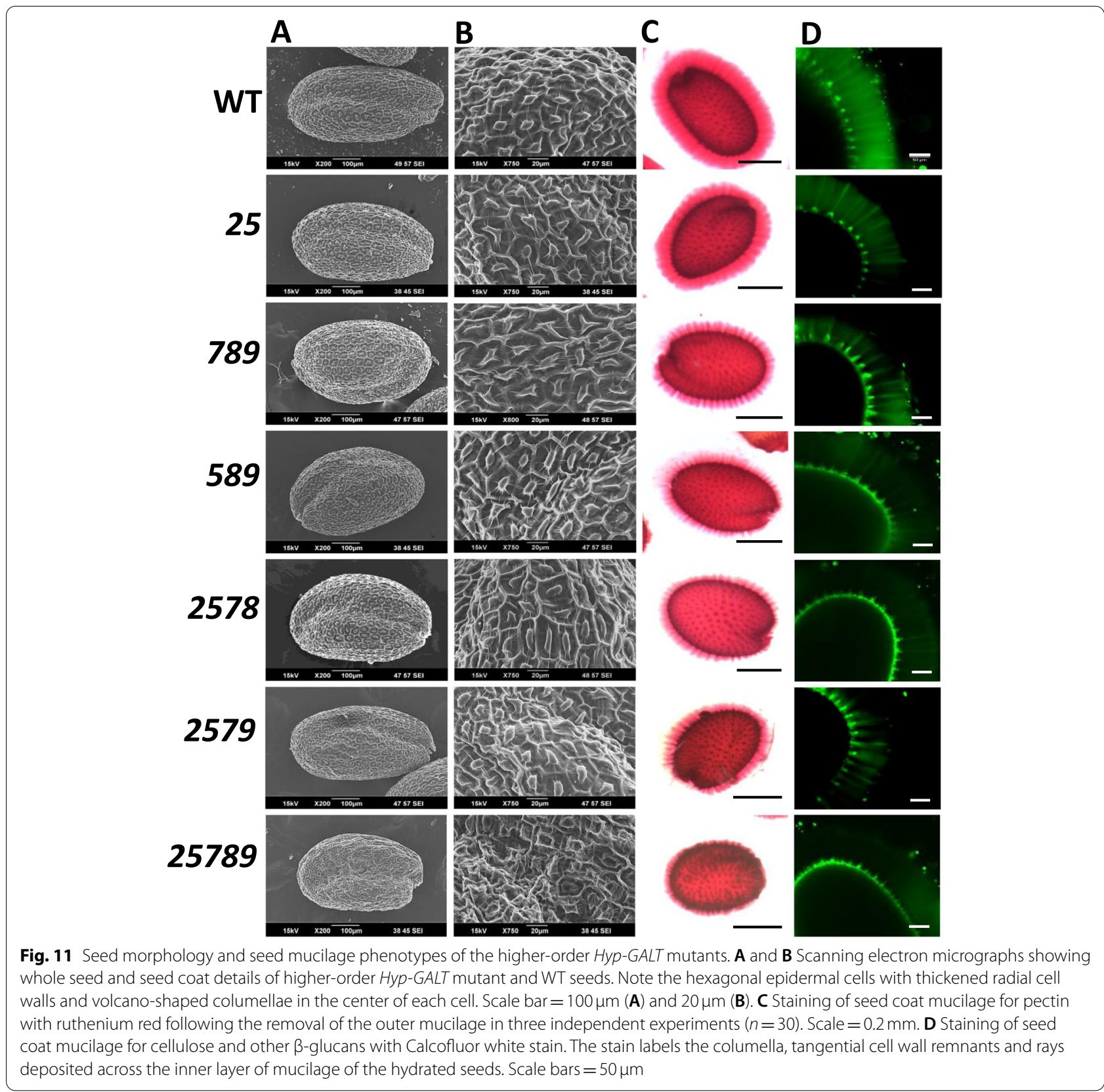

A (subclade III) of the GT31 phylogenetic tree for Arabidopsis [19]. These structural domain differences attributed to the GALECTIN domain (Fig. 1A) might indicate that the two subclades of $\beta-(1,3)$-GALTs may have multiple and distinct functions in $\mathrm{O}$-glycan biosynthesis compared to the other subclades which lack this domain. Until now, the function of galectin domain in these subclades is not known but all the members of these two subclades are known to add first galactose to Hyp residue of AGP protein backbones. Indeed, one member of this galectin-containing subclade V, GALT1 (At1g26810) was shown to encode a $(1,3)-\beta$-D-GalT involved in the biosynthesis of the Lewis a epitope on N-glycans $[19,41]$. Arguably, galectin domain might help in holding another galactose after the first one for $\beta-(1,3)$-GalT linkage, but further studies are required to reveal their exact mechanism of action. Thus, subgroup of galectin containing $\beta-(1,3)$-GalTs may have multiple and distinct functions in both $\mathrm{N}$-glycan and $O$-glycan biosynthesis.

Functional redundancy of both Hyp-GALT families is consistent with their substantial and widespread expression in almost all organs and growth stages, 


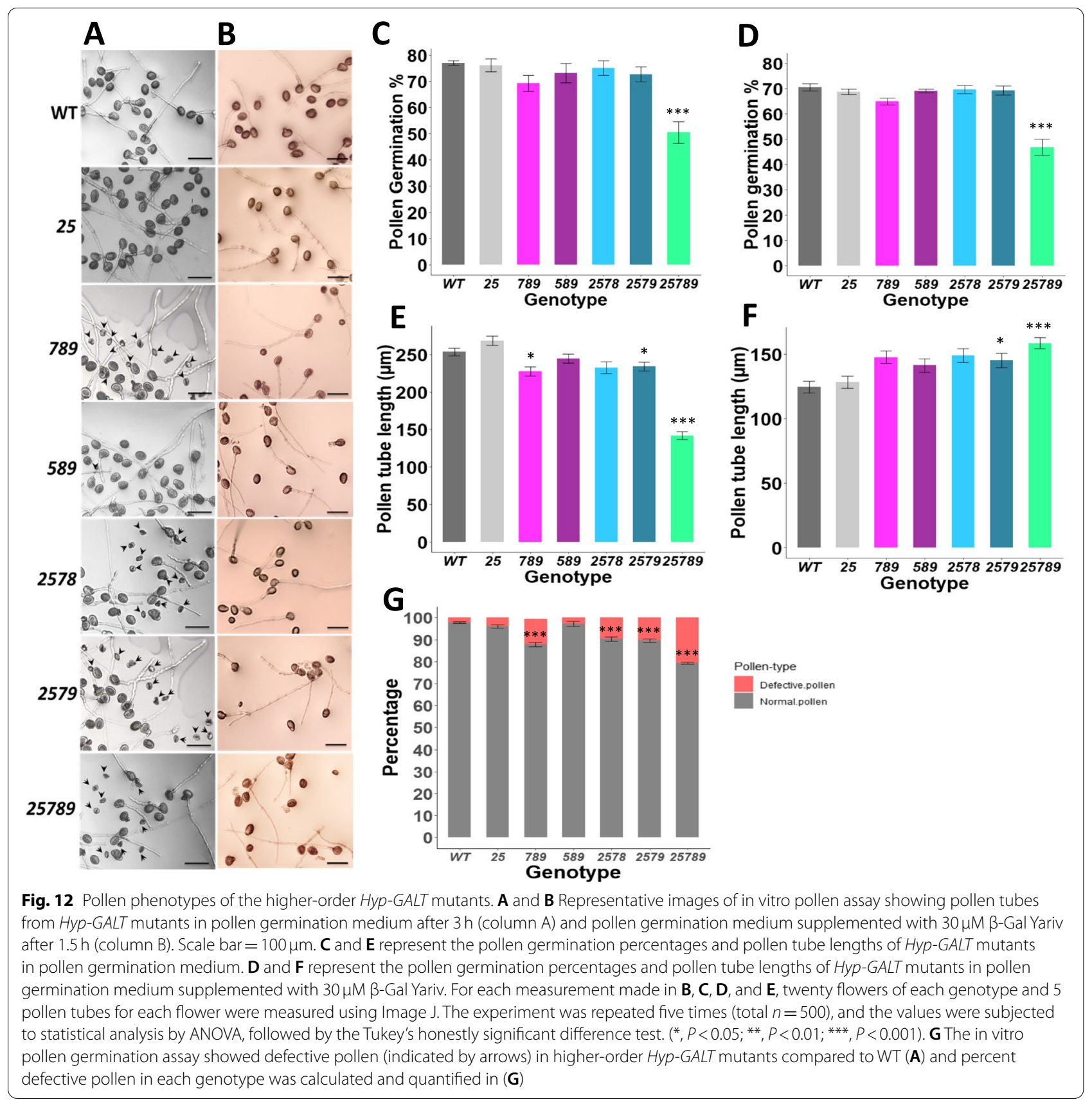

indicating the importance of these genes for variety of physiological functions in both vegetative and reproductive growth and development. Moreover, in previous studies prominent phenotypes were not reported for the single or double mutants [30,31,34], while the 789 triple knockout mutant exhibited various morphological alterations both in roots and aerial tissues [32]. Consequently, this study produced a set of higherorder knock-out mutants for five of the Hyp-GALT genes, including a quintuple mutant, followed by molecular, biochemical, and physiological characterization of these mutants to dissect the functional roles of each of these GALTs with respect to AGP biosynthesis and function in various plant organs. Upregulation of the rest of Hyp-GALT WT alleles in these multiple gene knock-outs is likely the direct consequence of gene compensation to mitigate the loss of Hyp-GALT protein functions (Fig. 2). 


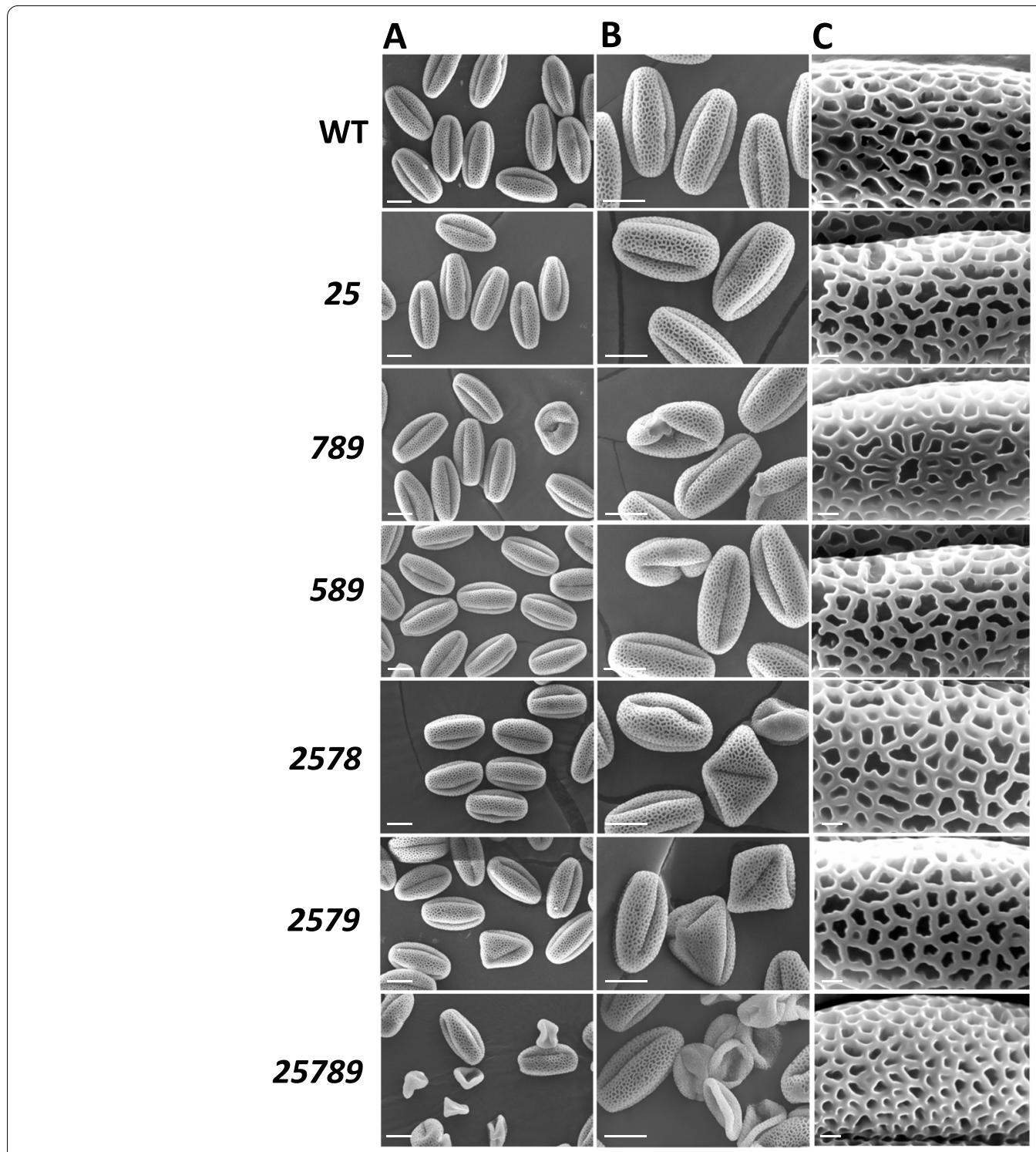

Fig. 13 Scanning electron micrographs of pollen grains of WT and the higher-order Hyp-GALT mutants. A, B, and C columns represent the pollen grains of WT, 25, 789, 589, 2578, 2579, and 25789 at different magnifications. Genotypes WT, 25, and 589 genotypes show the regular reticulate exine structure details of exine whereas 789, 2578, and 2579 show some misshaped and abnormal pollen. 25789 pollen grains demonstrated a higher percentage of collapsed and defective pollen with abnormal exine structure with smaller lacunae. Scale bars $=10 \mu \mathrm{m}$ in column $\mathbf{A}$ and $\mathbf{B}, 1 \mu \mathrm{m}$ in $\mathbf{C}$

Higher-order Hyp-GALT mutants have less glycosylated AGPs with reductions in gal and calcium content in various organs

Our results showed that higher-order Hyp-GALT mutants exhibited significant decreases in AGP content of flower, stem, root, silique, rosette leaf and cauline leaf in comparison to WT (Fig. 3). The greatest decrease in AGPs was seen in the 25789 mutant $(70-80 \%)$ and included all organs which were examined, indicating that these Hyp-GALT genes function redundantly in AGP glycosylation in these organs.
These findings are consistent with previous results that showed the 25 double mutants displayed a $43 \%$ reduction in $\beta$-Gal-Yariv precipitable AGPs compared to WT [33]. However, we only observed a $70 \%$ decrease in precipitable AGPs int the 789 triple mutant, whereas a 90\% decrease was reported previously [32]. Furthermore, monosaccharide composition analysis supported and extended the above results by showing a reduction in Gal content in silique and roots in almost all higherorder Hyp-GALT mutants (Fig. 4). 
A significant reduction in calcium content for the 25789 mutant only was observed (Fig. 5). AGPs, through their terminal GlcA residues, can interact with other cell wall components and/or with calcium to play roles in wall crosslinking and cellular signaling [42, 43]. Indeed, there are number of studies that provide evidence for AGP-AGP crosslinking as well as AGP-pectin and AGPpectin-arabinoxylan crosslinking [44-46]. Most notably, Arabinoxylan Pectin Arabinogalactan Protein 1 (APAP1) is one such complex in which AGP57C is chemically cross-linked to pectin and hemicellulose (i.e., arabinoxylan). Moreover, the GlcA residues on this AGP are known to be involved in the chemical crosslink to pectin [45]. A recent study by Lopez-Hernandez et al. [47] demonstrated that AGPs act as a calcium capacitor to bind and release cell-surface apoplastic calcium in a $\mathrm{pH}$-dependent manner. Here, the Hyp-GALT mutants, particularly the 25789 mutant, exhibited reduced/aberrant AG-polysaccharides which might have a reduced GlcA linking to calcium. Such biochemical alterations are clearly correlated and may be responsible for the impaired physiological phenotypes/functions observed here related to plant growth, development and reproduction.

\section{AGP glycosylation is critical for normal growth and development}

Higher-order Hyp-GALT mutants exhibited pleiotropic effects on vegetative growth under normal growth conditions, such that plant height, rosette leaf size, primary root growth and root hair length all decreased, while days to flowering and root hair density increased. Such growth defects were not observed for single or double mutants but were present in 789 triple mutants to some extent, indicating partial gene redundancy between the different GALTs. Taken together with our biochemical data, it is reasonable to conclude that critical threshold levels of glycosylated AGPs are required for normal growth and development.

AGPs have been implicated in various aspects of plant growth and development including cell proliferation and elongation, pattern formation, programmed cell death, cell-cell communication and hormone signaling $[6,11$, 48, 49]. Several AGP and AGP-related GT mutants are known to display such pleiotropic growth defects. For example, an agp19 mutant demonstrated smaller rosette leaves, delayed growth, shorter hypocotyls and inflorescence stems, and fewer siliques with less seeds [50]. Root hair sensitivity was previously observed in mutants for prolyl-4-hydroxylase genes ( $\mathrm{P} 4 \mathrm{H} 2, \mathrm{P} 4 \mathrm{H} 5, \mathrm{P} 4 \mathrm{H} 13)$, which displayed impaired root hair growth [51, 52]. Additionally, AGP30, a non-classical histidine-rich AGP is strongly expressed in roots and agp30 mutant revealed its function in in vitro root regeneration and in planta timing of seed germination [53] while AGP31 is strongly expressed in vascular tissues including the phloem and primary xylem and is suggested to play a role in root development [54]. Hence, knocking out multiple GALT genes likely affects such AGPs resulting in under-glycosylated AGPs, which in turn can prevent these AGPs from properly interacting with other cell wall or plasma membrane components in a structural or signaling capacity. In other words, our work is beginning to elucidate the critical roles that the carbohydrate moieties decorating AGPs play in normal growth and development.

\section{AGP glycosylation is important for root cell expansion and growth under stress conditions}

All Hyp-GALT mutants display root-tip swelling in response to salt stress. These findings are supported by the higher levels of expression for GALT7, GALT8 and GALT9 compared to GALT2 and GALT5 in the roots (Supplemental Fig. 1). However, more pronounced root tip swelling was found in 789 and 25789 in comparison to 25,2578 , and 2579 , and which could be recovered in 25, 2578, and 2579 unlike 789 and 25789 (Supplemental Fig. 5) This argues for the stronger involvement of GALT7, GALT8 and GALT9 in root growth. Previously, similar reduced root growth in the presence of elevated $\mathrm{NaCl}$ was also observed in the FUT4 and FUT6 mutants, which are defective in AGP fucosylation [26, 27]. Our root swelling observations with the Hyp-GALT mutants coincide with and extend previous observations by [34]. We now believe that the GALT2/GALT5-dependent glycosylation of an SOS5 AGP which might act as cell wall integrity sensor for perceiving and signaling differences in turgor pressure when subjected to elevated salt, can be extended to include other GALTs, namely GALT7, GALT8 and GALT9.

All the higher order Hyp-GALT mutants displayed stronger insensitivity of the roots to $\beta$-Gal-Yariv growth inhibition. These results are in agreement with previous findings that single galt 2-6 mutants, galt 2 galt 5 double mutant, galt7 galt8 galt9, galt3 galt4 galt6 triple mutants and galt 2 galt 3 galt 4 galt 5 galt 6 quintuple mutants were shown to be less sensitive to $\beta$-Yariv inhibition of root growth [31, 35]. In our study here, 25789, 2579, 2578 higher order mutants exhibited the greatest root elongation in comparison to the double and triple mutants, indicating the partial redundancy of Hyp-GALTs. The fact that $\beta$-glycosyl-Yariv reagent inhibits cell proliferation by binding to AGPs and forming insoluble complexes or can even lead to cell death explains the lesser growth inhibitory effects experienced in mutants due to reduced or under glycosylated AGPs. 


\section{Altered AGP glycosylation affects cell wall structure}

Plant mechanical strength primarily depends on cell wall composition. Although AGPs represent $<10 \%$ of the complex network of cell wall polysaccharides, multiple studies have reported their effect on mechanical strength by modifying and customizing the synthesis and architecture of other major components and hence, maintaining the integrity of the cell wall. The 25789 quintuple mutants exhibited thinner stem xylem fibers, vessel and interfascicular fiber cell walls compared to WT. These cell wall defects are similar to what has previously been observed in group A fasciclin-like AGPs of Arabidopsis, fla11fla12 double mutants that displayed reduced tensile strength and stiffness, an increase in cellulose microfibril angle, reduction in cellulose, galactose and arabinose content and an effect on stem biomechanics [55]. Another mutant belonging to group B fasciclin-like AGPs, fla16 exhibited moderate glycosylation and reduced stem length, also demonstrated its role in plant secondary cell wall synthesis and function [56]. Moreover, a brittle stem and zebra leaf mutant $b z 1$ of rice which encodes a functional UDP-galactose/glc epimerase exhibited a significantly decreased AGP levels, and also displayed reduced mechanical strength along with altered cell wall structure and composition [57]. This supports the idea that AGPs somehow interact with the scaffold proteins that align microtubules and cellulose microfibrils, eventually disorganizing their orientation [58-60]. Although the details about how AGPs structurally affect other cell wall components remain unclear, the monosaccharide composition analysis along with the changes in cell wall structure indicates that under-glycosylated AGPs in the Hyp-GALT mutants alter the cell wall architecture.

\section{AGP glycosylation affects seed germination, morphology and mucilage accumulation}

Germination rates of seeds were reduced for the 2578 and 2579 mutants, but the germination percentage was reduced dramatically only for $25789(\sim 55-60 \%$ germination) (Fig. 6). The germination defects are consistent with the higher gene expression of these five GALT genes in seed coat differentiation during early embryogenesis (Supplemental Fig. 2). SEM images of dry, WT seeds display an epidermal layer consisting of hexagonal cells, thickened radial cell walls and a raised structure known as the columella. In the mutants, the columellae of the seed epidermal cells are irregular in shape and reduced in size. Seed development has two major phases, embryo development and seed maturation [61]. Thus, 25789's failure to achieve complete germination may be due to irreparable damage caused to the embryo during embryogenesis or to structural alterations in the 25789 seed coats during the dry storage of seeds (Fig. 11A).
Unlike WT seeds, the seeds of higher-order Hyp-GALT mutants extrude a reduced amount of adherent mucilage upon hydration, which was more pronounced than observed in 25 and 789 (Fig. 11). In addition, all the mutants show a substantial reduction of cellulosic rays in the seed coat mucilage layer. Although AGPs represent a small portion of the seed coat mucilage, they play important roles [62]. Harpaz-Saad et al., (2011) [40] reported that synthesis and deposition of cellulosic rays in seed coat mucilage were affected by both FEI2, a leucine-rich receptor-like kinase, and SOS5, a fasciclin-like AGP, with a concomitant increase in solubility of the pectin. Thus, our results indicate that glycosylated AGPs are involved in maintaining the adherent mucilage layer in seeds, most likely through interactions with other mucilage polysaccharides like pectin.

\section{AGP glycosylation reduces seed yield and affects male gametophyte}

The seed set, silique length and total number of siliques were reduced in various higher-order Hyp-GALT mutants accompanied by the defective pollen, reduced anther size, and pollen tube lengths (Figs. 10 and 13). Also, $\beta$-Yariv induced growth inhibition for pollen tubes in Hyp-GALT mutants similar to that observed in the roots. The Hyp-GALT mutants phenocopied kns4 mutants, which are defective in the KNS4 gene encoding a type II arabinogalactan $\beta$-(1,3)-galactosyl-transferase in the GT31 family and showed reduced fertility attributed to aborted pollen having an abnormal pollen exine structure [20,63]. Indeed, several AGP genes show high expression in hydrated or mature pollen and pollen tubes in Arabidopsis, including AGP6, AGP11, AGP15, AGP21, AGP22, AGP23, AGP24 and AGP40 [12]. Heterozygous agp6 agp11 knockouts of two pollen-specific functionally redundant genes, $A G P 6$ and $A G P 11$, had fewer seeds per silique, which was attributed to a reduction in pollen germination as well as pollen tube length [9]. It is proposed that AGPs in the cell wall of pollen tubes can be recycled to maintain their concentration levels at the pollen tube apex, as this may be necessary for them to perform a signaling role for pollen tube guidance $[11,42,64]$. Also, AGPs affect the structure of the cell wall by changing the localization of other cell wall components, suggesting their critical role in the mechanical properties of the pollen cell wall [65]. All GALTs examined here, namely GALT2, GALT5, GALT7, GALT8 and GALT9, are likely involved in the glycosylation and hence the function, of pollen specific AGPs.

Clearly, with respect to the mechanism of action of AGPs in reproduction, the interactive sugar surfaces formed by type-II AGs on AGPs play a primary role in their reproductive functions. A study in apple supports 
the hypothesis of spatiotemporal regulation of secretion of glycoproteins in the style and ovules upon pollen tube arrival, suggesting a pivotal role for AGPs in fertilization $[66,67]$. Even more interesting, AMOR, a sporophytic ovular factor derived from side chains of AGPs primes pollen tubes to respond to female gametophyte-derived attraction signals in the wishbone flower $[68,69]$. Our work here on the Hyp-GALTs only serve to strengthen and reinforce this idea that type-II AGs on AGPs are critical to their function in reproductive tissues, most likely by serving as signaling molecules and/or nutrition sources during pollination, male gametophyte development, and fertilization.

\section{Conclusions}

In summary, a comprehensive physiological and biochemical analysis of a set of mutants for five out of the eight known Hyp-GALT in two GT31 subfamilies was conducted in order to dissect their functional contributions and partial gene redundancies in different Arabidopsis organs. Despite the additive and pleiotropic effects of GALT2, GALT5, GALT7, GALT8 and GALT9 on vegetative and reproductive growth phenotypes such as rosette size, insensitivity to $\beta$-Yariv reagent, seed set and pollen development, some phenotypes exhibited more substantial regulation by specific GALTS and were correlated with their expression patterns. Specifically, GALT7, GALT8 and GALT9 had a dominative effect in controlling primary root growth, root tip swelling under salt stress, plant height, silique length, and pollen viability, whereas GALT2 and GALT5 had more pronounced effects on seed morphology, germination, and seed set. Interestingly, altered/under-glycosylated stem AGPs most likely affect the cell wall structure in the Hyp-GALT mutants and lead to their stunted growth. Severe effects on AGP glycosylation in various plant organs of the higher-order HypGALT mutants were demonstrated by decreases in total Yariv-precipitated AGPs and Gal, and calcium, which in turn impact AGP function.

Finally, this study raises several questions for future studies. 1. Do these eight enzymes act on all AGPs or on a subset of AGPs? 2. What is the exact structural arrangement of the AG polysaccharides and Hyp-polysaccharide profiles in these mutants compared to WT? 3. Are there additional AGP-specific Hyp-GALTs that remain to be identified? 4. What is the mechanism or mode of action by which AGPs carry out their functions and precisely how are AG polysaccharides involved?

\section{Methods}

Plant materials and growth conditions

A. thaliana (Columbia-0 ecotype) was obtained from the Arabidopsis Biological Research Center (ABRC),
Columbus, Ohio, USA and used as WT. The galt2 galt5 homozygous T-DNA mutant was previously generated in our lab [30]. The hpgt1 hpgt2 hpgt3 homozygous T-DNA mutant was obtained as a kind gift from Dr. OgawaOhnishi's lab [32]. These double and triple mutants were crossed to obtain the different combinations of higherorder Hyp-GALT mutants for this study. Plants were grown in soil for mutant screening, seed harvesting, and growth-stage phenotypic analysis. Plant age was counted in days after germination (DAG) whereby 1 DAG defines the first day on which green cotyledons became visible. For root harvesting, plants were grown hydroponically in germination medium and basal nutrient medium using a hydroponic growth system as described previously [70]. For phenotypic analysis of root growth, plants were grown on Murashige and Skoog (MS) medium (Caisson Laboratories, North Logan, UT, USA) containing $1 \%$ sucrose and $1 \mathrm{~g} / \mathrm{L}$ Phytagel. All plants were grown under long-day conditions $\left(16 \mathrm{~h}\right.$ of light $/ 8 \mathrm{~h}$ of dark, $22^{\circ} \mathrm{C}$, $60-70 \%$ relative humidity) in growth chambers at a light intensity of $122 \mu \mathrm{mol} \mathrm{m}^{-2} \mathrm{~s}^{-1}$.

\section{PCR genotyping}

Genomic DNA was extracted from fresh young leaves, which were homogenized in a tissue disrupter using metal beads. Primer locations are indicated in Fig. 1A, and the corresponding primer sequences for genotyping are listed in Supplementary Table 2. To increase the accuracy of genotyping to isolate multiple mutants, two independent PCR reactions were used to detect mutant and WT alleles, instead of using multiplex PCR. To amplify the mutant allele, a primer set (i.e., a T-DNA primer called LBb1.3 and a gene-specific primer) was used. To amplify the WT allele, two gene-specific primers that hybridize adjacent to a T-DNA insertion site were used.

\section{Quantitative RT-PCR}

For RNA extraction, flowers of all genotypes were harvested at 40 DAG as the expression levels were high in the inflorescence and carpel and snap-frozen in liquid nitrogen. Samples were ground to a fine powder and total RNA was extracted using Trizol reagent (Life Technologies, Grand Island, NY, USA). For real time-quantitative PCR (qRT-PCR), $1 \mu \mathrm{g}$ of total RNA was treated with DNaseI (New England Biolabs) and used for cDNA synthesis. First-strand cDNA synthesis was performed with an oligo (dT20) primer and Superscript III reverse transcriptase (Thermo Scientific). The qPCR was set up using PerfeCT SYBR Green SuperMix (Quanta Biosciences). A total $20 \mu$ reaction mixture contained $10 \mu \mathrm{l}$ of PerfeCT SYBR Green SuperMix, $4 \mu \mathrm{l}$ of $10 \mathrm{x}$ diluted cDNA, and $0.6 \mu \mathrm{l}$ each of forward/ reverse primer $(10 \mu \mathrm{M})$. Expression levels were 
analyzed by qRT-PCR performed in a 96-well plate on an AriaMx Real-time PCR machine (Ohio University Genomics Facility). Reaction conditions were: $95^{\circ} \mathrm{C}$ for $5 \mathrm{~min}, 35 \mathrm{cycles}$ of $95^{\circ} \mathrm{C}$ for $10 \mathrm{~s}, 60^{\circ} \mathrm{C}$ for $10 \mathrm{~s}, 72^{\circ} \mathrm{C}$ for $10 \mathrm{~s}$, and a final step of $72^{\circ} \mathrm{C}$ for $4 \mathrm{~min}$. Primer efficiency measurements and quantification cycles $(\mathrm{Cq})$ were calculated using AriaMx Version 1.5 software from Agilent technologies (https://www.agilent.com/en/produ ct/real-time-pcr-(qpcr)/real-time-pcr-(qpcr)-software/ ariamx-software-download). For quantification, ACTIN gene (At3G18780) was used as reference gene and the relative gene expression data were generated using WT plants as a calibrator. Oligonucleotide sequences used for qRT-PCR are listed in Supplementary Table 3. All qRT-PCR experiments were performed in biological triplicates.

\section{AGP quantification by $\beta$-D-Gal-Yariv reagent}

AGPs were extracted from Hyp-GALT mutants and WT using $\beta$-D-Gal-Yariv reagent for precipitation as described previously [71] with modifications. Briefly, rosette leaves, cauline leaves, stems, siliques were collected from 40 DAG from all genotypes whereas flowers were collected at 50 DAG for 25789 and at 40 DAG for the rest of genotypes. Exactly $0.25 \mathrm{~g}$ of each tissue was ground to a fine powder in presence of liquid nitrogen and mixed with $1 \mathrm{~mL} 2 \% \mathrm{CaCl}_{2}$ followed by shaking at $200 \mathrm{rpm}$ for $2-3 \mathrm{~h}$ at room temperature. The tissue homogenates were centrifuged at $13,000 \mathrm{~g}$ for $15 \mathrm{~min}$. To $500 \mu \mathrm{l}$ of the supernatant separated in a $1.5 \mathrm{~mL}$ centrifuge tubes, $200 \mu \mathrm{l}$ of $\beta$-D-Gal-Yariv dissolved in $2 \%$ $\mathrm{CaCl}_{2}(1 \mathrm{mg} / \mathrm{mL})$ was added. $500 \mu \mathrm{l}$ of $2 \% \mathrm{CaCl}_{2}$ was used as a control. After $2 \mathrm{~h}$ of precipitation by $\beta$-D-Gal-Yariv at room temperature, the insoluble $\beta$-Gal-Yariv-AGP complex was collected by centrifugation at $13,000 \mathrm{~g}$ for $15 \mathrm{~min}$. The pellet was washed twice with $2 \% \mathrm{CaCl}_{2}$ and then dissolved in $20 \mathrm{mM} \mathrm{NaOH}$. The dissolved AGPs were quantified by measuring absorbance at $\mathrm{OD}_{420}$. Different concentrations of gum arabic (10-300 $\mu$ g) (SigmaAldrich, St. Louis, MO, USA) dissolved in $2 \% \mathrm{CaCl}_{2}$ were used to obtain an AGP standard curve. All measurements for different tissues were made from four biological replicates.

\section{Monosaccharide composition analysis by HPAEC-PAD}

AGPs were extracted from siliques of 40-day-old WT and Hyp-GALT mutant plants. Whereas roots were harvested from hydroponically grown plants at 40 DAG. AGPs from all tissues were extracted as described previously [71], with minor modifications. For both monosaccharide composition and AGP profiling, AGPs were extracted from $\sim 8-10 \mathrm{~g}$ of silique and root tissues which were snap-frozen with liquid nitrogen, ground to a fine powder and mixed with $2 \% \mathrm{NaCl}$ ( 1 part tissue: 4 parts of $2 \% \mathrm{NaCl}$ ), followed by shaking at $200 \mathrm{rpm}$ for $3 \mathrm{~h}$ at room temperature. Samples were centrifuged for $30 \mathrm{~min}$ at $13,000 \mathrm{~g}$ at room temperature. Then, $2 \mathrm{~mL}$ of $\beta$-D-Gal-Yariv reagent dissolved in $2 \% \mathrm{NaCl}(2 \mathrm{mg} / \mathrm{mL})$ was added to the supernatant and allowed to precipitate overnight. The precipitated AGPs were collected by centrifugation at $2000 \mathrm{~g}$ for $20 \mathrm{~min}$, washed with $2 \%$ $\mathrm{NaCl}$ twice, resuspended in $2 \mathrm{~mL}_{2} \mathrm{O}$. Sodium dithionite was added and incubated for $15 \mathrm{~min}$ at $50^{\circ} \mathrm{C}$ until the mixture was decolorized. The resulting solution was desalted on a PD-10 column (GE Healthcare) that had been equilibrated with water, and the eluate was freezedried overnight.

For monosaccharide composition analysis, approximately $500 \mu \mathrm{g}$ of AGPs were hydrolyzed using $2 \mathrm{~N}$ TFA, at $121^{\circ} \mathrm{C}$ for $90 \mathrm{~min}$ followed by removal of TFA by drying under a $\mathrm{N}_{2}(\mathrm{~g})$. Samples were washed with isopropanol thrice before dissolving in $500 \mu \mathrm{l}$ of $0.1 \mathrm{mM}$ cellobiose as an internal standard. A standard sugar mixture $(0.2 \mathrm{mM}$ each of fucose, rhamnose, arabinose, galactose, glucose, xylose, mannose, galacturonic acid, and glucuronic acid) was employed for determining molar amounts of individual sugars by single point internal standard quantification. All samples along with standards were subjected to high-performance anion exchange chromatography with pulsed amperometric detection (HPAEC-PAD) on a Dionex ICS-500 instrument equipped with a Dionex PA-20 system (Thermo Fisher Scientific, Sunnyvale, CA, USA) essentially as described by Øbro et al., (2004) [72]. Monosaccharide compositions were calculated as averages $(+/-$ standard error) of biological triplicates and are displayed as molar percentages.

\section{Calcium binding assay}

For the calcium binding assay, we assayed $50 \mu \mathrm{l}$ of AGP stocks $(10 \mu \mathrm{g} / \mathrm{mL}$ in Mili-Q water) of WT and Hyp-GALT mutants' stems, siliques, flowers and roots used for HPAEC before as described previously [73, 74]. A commercial calcium calorimetric assay kit (MAK022, Sigma-Aldrich, St. Louis, MO, USA) was used for calcium measurement as per manufacturer's protocol.

\section{Germination experiment}

Seeds of WT and Hyp-GALT mutants were sterilized, stratified at $4{ }^{\circ} \mathrm{C}$ for 3 days in the dark, and then sown on $1 / 2$ MS medium and $1 \%$ sucrose agar plates. Germination percentages and rates were counted at $12 \mathrm{~h}$ intervals for up to $72 \mathrm{~h}$ after sowing, and radicle lengths were analyzed at $48 \mathrm{~h}$. Approximately 36 seeds were sown for each genotype with four replicates. 


\section{Aerial plant phenotyping}

WT and Hyp-GALT mutants grown on soil were measured for their plant height at 30, 40, and 50 DAG and compared to WT (control) plants under normal conditions $(n=15)$ in three independent experiments. Measurement of flowering time was performed as previously described [75, 76]. Flowering time was scored as the number of DAG to the first appearance of buds at the apex and the total number of rosette leaves after the main stem has bolted $1 \mathrm{~cm}$. For each replicate, flowering time was recorded from at least 15 plants per genotype in three independent experiments. Data are the averages of three replicates. Statistical significance was determined using ANOVA.

\section{Root and root hair growth}

WT and Hyp-GALT mutant seeds were sterilized, stratified at $4{ }^{\circ} \mathrm{C}$ for 3 days in the dark, and then sown on $1 / 2$ MS medium and 1\% sucrose agar plates. Four-day-old seedlings were transferred onto $1 / 2 \mathrm{MS}$ agar plates and kept in a growth chamber at $22^{\circ} \mathrm{C}, 16 \mathrm{~h}$ light $/ 20^{\circ} \mathrm{C}, 8 \mathrm{~h}$ dark photoperiod. Primary root length of each genotype was measured from $3 \mathrm{~d}$ to $8 \mathrm{~d}$ after sowing under normal conditions $(n=15)$ in three independent experiments. Root-hair length and root-hair density at an area $3 \mathrm{~mm}$ to $5 \mathrm{~mm}$ from the root tip, 6 days after transfer on $1 / 2$ MS media (10 d old-seedlings) were measured. To ensure comparable results, quantification of root hairs length was performed using 10 seedlings for of the Hyp-GALT mutants and WT, and 25 root hairs from each root were measured for analysis (total root hairs $=250$ (genotype). Root-hair density was counted for 50 seedlings in total/genotype in three independent experiments.

\section{Aberrant root and root hair morphology under conditional stress}

For root tip analysis, seeds were germinated in $1 / 2 \mathrm{MS}$ plates and grown for 3 days before transferring to MS plates supplemented with $100 \mathrm{mM} \mathrm{NaCl}$. Root tips of plant seedlings for all genotypes grown for $10 \mathrm{~d}$ and visualized under a Nikon SMZ1500 stereomicroscope coupled with a CCD Infinity 2 camera. To calculate a change in root length under salt stress, root length was measured at $7 \mathrm{~d}$ and $14 \mathrm{~d}$ after transfer by capturing images using a CCD camera, which were analyzed through image analysis freeware (ImageJ; http://rsb.info.nih.gov/ij/). For monitoring root growth in response to $\beta$-Gal-Yariv reagent, WT and Hyp-GALT mutant seedlings were grown on $1 / 2$ MS plates for 4 days before they were transferred to $1 / 2$ MS plates supplemented with $50 \mu \mathrm{M} \beta$-Gal-Yariv reagent. Root length was determined on low magnification $(\times 10)$ digital images captured using a CCD camera by using image analysis freeware (ImageJ). To calculate an increase in root length in $\beta$-Gal-Yariv supplemented $1 / 2$ MS media, root length was measured at $7 \mathrm{~d}$ and $14 \mathrm{~d}$ after transplanting 15 seedlings in three independent experiments.

\section{Seed set evaluation}

The basal 15 mature siliques on the inflorescence stem at 42 DAG for 10 plants per genotype were collected from, and silique lengths were measured. For seed number, the 15 basal siliques on main inflorescence stem of 20 plants per genotype were decolorized by incubation in $70 \%$ ethanol at $37^{\circ} \mathrm{C}$ overnight and were visualized under a Nikon SMZ1500 stereomicroscope coupled with a CCD Infinity 2 camera. For reciprocal cross-pollinations, 20 flowers from WT and 25789 quintuple mutants were selected at stage 12 . These flowers were emasculated before pollinating them with fresh pollen obtained from flowers at stage 13. After 10 days, siliques were collected from these flowers to examine seed set.

\section{Scanning electron microscopy}

Seeds and pollen samples were dry-mounted on aluminum stubs, covered by a $10 \mathrm{~nm}$ coat with palladium in a sputter coater (Anatech HUMMER 6.2 Sputtering System), and observed using a scanning electron microscope (SEM JEOL JSM-6390, HV/LV Tungsten/ LaB6, Jeol USA Inc. 2012) equipped with an Energy Dispersive X-ray Spectroscopy (EDS) detector, with an accelerating voltage of $15 \mathrm{kV}$. Photographs were taken using SEM Control User Interface version 8.5 software at the Institute for Corrosion and Multiphase Technology, Ohio University. Every genotype was examined in three independent groups of roughly 20 seeds and pollen each.

\section{Transmission electron microscopy and toluidine blue staining}

For TEM observations, the basal internodes of inflorescence stems of 6-week-old plants with the same flowering date were collected for WT and 25789 mutant. Briefly, the internodes were fixed in FAA overnight and embedded in spur resin to obtain $70 \mathrm{~nm}$ ultrathin sections by using an ULTRACUT N ultramicrotome (Reichert-Nissei, Tokyo, Japan) with a diamond knife and mounted on copper grids essentially as described by Suzuki et al. (2008) [63]. Specimens were viewed by FEI TEcnai G2 Spirit TEM using the Campus Microscopy and Imaging Facility at the Ohio State University.

Sections $(1 \mu \mathrm{m})$ of resin-embedded anthers as prepared for TEM were mounted on a glass slide, stained with a toluidine blue staining solution $[0.5 \%(\mathrm{w} / \mathrm{v})$ toluidine blue, $0.5 \%(\mathrm{w} / \mathrm{v})$ sodium borate], and the slides heated 
on a hot plate for $20 \mathrm{~min}$. After washing out the stain, the specimen was viewed under a light microscope.

\section{Cytochemical staining of seeds}

Seeds of all indicated genotypes were pre-hydrated in water for $1 \mathrm{~h}$ with shaking $(200 \mathrm{rpm})$ to remove nonadherent mucilage and stained with $0.01 \%$ ruthenium red and calcofluor for $30 \mathrm{~min}$ each as described by [8, 40]. Ruthenium red stained seeds were examined under a Nikon SMZ1500 stereomicroscope coupled with a CCD Infinity 2 camera. For calcofluor staining, excitation was measured with $405 \mathrm{~nm}$ laser diode. Imaging was done using a Zeiss LSM 510 confocal microscope at Ohio University.

\section{Chemical analysis of adherent and non-adherent mucilage}

Alterations in soluble versus adherent mucilage were assessed using the method reported by Harpaz-Saad et al. (2011) [40]. Three independent samples of $100 \mathrm{mg}$ of seeds were extracted sequentially with $0.2 \%$ ammonium oxalate, $0.2 \mathrm{~N} \mathrm{NaOH}$ and $2 \mathrm{~N} \mathrm{NaOH}$ for $1 \mathrm{~h}$ each with vigorous shaking at $37^{\circ} \mathrm{C}$. Both sodium hydroxide extractions contained $3 \mathrm{mg} / \mathrm{ml}$ sodium borohydride to prevent end-degradation and were neutralized with acetic acid. Total sugar $(\mu \mathrm{g} / \mathrm{mg}$ seed) was determined with a phenol-sulfuric assay as reported by Basu et al. (2015) [31]. Seeds used for each chemical analysis were collected from mutant and control plants cultivated together.

\section{In vitro pollen germination assay}

Flowers collected from WT and Hyp-GALT mutant plants 1 to 2 weeks after bolting were used for the examination of pollen tube phenotypes. Individual open flowers were germinated in vitro as described previously [77, 78], on solid germination medium $\left(0.01 \% \mathrm{H}_{3} \mathrm{BO}_{3}, 1 \mathrm{mM} \mathrm{Ca}\left(\mathrm{NO}_{3}\right)_{2}, 1 \mathrm{mM} \mathrm{KCl}, 1 \mathrm{mM}\right.$ $\mathrm{CaCl}_{2}, 10 \%$ sucrose, $0.03 \%$ casein enzymatic hydrolysate, $0.01 \%$ myo-inositol, $0.1 \mathrm{mM}$ spermidine, $10 \mathrm{mM}$ GABA, $500 \mu \mathrm{M}$ methyl jasmonate and $1.0 \%$ low-melting agarose, $\mathrm{pH} 7.5$ and $30 \mu \mathrm{M} \beta$-Gal-Yariv reagent) at $22^{\circ} \mathrm{C}$ and $100 \%$ humidity in the dark. Pollen tube germination rates were calculated by dividing the total number of germinated tubes by the number of grains. Images and measurements of pollen tubes were done at $10 \times$ magnification in a Nikon Phot-lab2 microscope coupled with a SPOT RT color CCD camera and SPOT 4.2 analysis software.

\section{Abbreviations}

AGP: Arabinogalactan-protein; HRGP: Hydroxyproline-rich glycoprotein; TEM: Transmission electron microscopy; HPAEC-PAD: High-Performance Anion-Exchange Chromatography with Pulsed Amperometric Detection; GlcA: Glucuronic acid; AG: Arabinogalactan; GPI: Glycosylphosphatidylinositol; Hyp-GALT: Hydroxyproline-galactosyltransferase; Gal: Galactose; CAZy: Carbohydrate active enzyme (database); GT: Glycosyltransferase; WT: Wild-type; ACC: Amino-cyclopropane-carboxylate; DAG: Days after germination.

\section{Supplementary Information}

The online version contains supplementary material available at https://doi. org/10.1186/s12870-021-03362-2.

Additional file 1: Supplemental Figure 1. In silico gene expression profiles of the eight Hyp-GALT genes in Arabidopsis organs/ tissues. Araport (Cheng et al., 2016) utilizes 113 public RNA-seq data sets along with annotation contributions from NCBI, UniProt, and labs conducting Arabidopsis thaliana research to obtain gene expression values based on transcript abundance normalized in accordance with a reference gene in the experiment. Supplemental Figure 2. Gene expression analysis of the eight Hyp-GALT genes during seed development. BAR eFP browser (Lee et al., 2010) displays gene expression profiles based on laser-capture micro-dissected seeds during various stages of seed development. Supplemental Figure 3. Growth phenotype of WT and higher-order Hyp-GALT mutants on soil. A.WT and mutant seedlings were sown on $1 \frac{1}{2}$ MS media and transferred to soil at 10 DAG; photos were taken over a period of four weeks on soil. Rosette sizes of 789, 2578, 2579 and 25789 were smaller than wild type throughout the 4 weeks. B. Total number of rosette leaves were counted for mutants and WT plants after the main stem bolted $1 \mathrm{~cm}$. Data for number of rosette leaves are means $\pm S E$ of measurements from three independent experiments (total $n=50$ ). An analysis of variance (ANOVA) on these mutants yielded no significant variation among conditions. DAG, days after germination. Supplemental Figure 4. Quantification of root hair length and root hair density of wild type and higher-order Hyp-GALT mutants on $1 / 2$ MS media at 7 DAG. Data for root hair length are means \pm SE of measurements from three independent experiments $(n=80)$. Data for root hair density are means \pm SE of measurements from three independent experiments (total $n=50$ ). An analysis of variance (ANOVA) on these mutants yielded significant variation among conditions. A post hoc

Tukey test was applied to see which groups were significantly different from wild type (Col-0). Asterisks indicate significantly reduced root hair length and density compared with WT. ${ }^{*} P<.05,{ }^{* *} P<0.005,{ }^{* * *} P<0.001$. DAG, days after germination. Supplemental Figure 5. Salt induced inhibition of vertically grown primary roots of WT and higher-order Hyp-GALT mutants on $1 / 2$ MS supplemented with $100 \mathrm{mM} \mathrm{NaCl}$. A. Seedlings of WT and mutants were grown vertically on $1 / 2$ MS media for 4 DAG and pictures were taken 7 days after transfer to $1 / 2$ MS supplemented with $100 \mathrm{mM} \mathrm{NaCl}$. Scale bar $=1 \mathrm{~cm}$. B. 10 days after transfer to $1 / 2 \mathrm{MS}$ supplemented with $100 \mathrm{mM} \mathrm{NaCl}$. Scale bar $=1.0 \mathrm{~mm}$. C. Root elongation (i.e. increase in root length of 4-day-old seedlings after transfer onto $1 \frac{1}{2}$ MS supplemented with $100 \mathrm{mM} \mathrm{NaCl}$ ) was measured after 7 , 14 and 21 days. Data are means \pm SE of measurements from three independent experiments (total $n=40$ ). An analysis of variance (ANOVA) on these mutants yielded significant variation among conditions. A post hoc Tukey test was applied to see which groups were significantly different from WT. ${ }^{*} P<.05,{ }^{* *} P<0.005,{ }^{* *} P<0.001$. DAG, days after germination. Supplemental Figure 6. Mean seed set of the basal 15 siliques on the main inflorescence of the Hyp-GALT mutants compared to WT. The fifteen siliques (starting from the base) were used to quantify seed set in 45-days-old plants grown on soil. Data presented are mean \pm SD ( $n=20$ plants in three independent experiments). Supplemental Figure 7. Mean silique lengths of the basal 15 siliques on the main inflorescence of the Hyp-GALT mutants compared to WT. The fifteen siliques (starting from the base were used to quantify silique length in 45 -day-old plants grown on soil. Data presented are mean \pm SD ( $n=10$ plants from two independent experiments). Supplemental Figure 8. Higher-order Hyp-GALT mutant flower morphology compared to WT flower morphology. The 25789 mutant had smaller fertile flowers compared to WT, but the floral organization was similar ( $n=10$ flowers from 5 plants each). Scale bar=1.0 
mm. Supplementary Table 1. Information on the Hyp-GALT enzymes, genes, and their genetic mutants. The two independent GALT2-6T-DNA lines have been characterised and they had same phenotypes as reported by Basu et al. (2015) [30] and Basu et al. (2015) [31]. The GALT7-9T-DNA insertion lines were identified and confirmed by Ogawa-Ohnishi and Matsubayashi (2015) [32]. Also, the subcellular localization of GALT2-9 mentioned here were reported in these studies. Supplementary Table 2. Oligonucleotides used for genotyping of the Hyp-GALT mutants. Supplementary Table 3. Oligonucleotide sequences used for aRT-PCR of the Hyp-GALT mutants. Supplementary Table 4. The Hyp-GALT mutants display reduced total sugars $(\mu \mathrm{g} / \mathrm{mg}$ seed \pm $\mathrm{SE})$ compared to WT in Arabidopsis seed mucilage.

\section{Acknowledgements}

We thank Stacy Welker and Marley Mckind for helping with the mutants screening and phenotypic analyses. We also thank Yuan Zhang and Debarati Basu for their critical comments on the manuscript. This work was supported by the A\&S Graduate Student Research Fund of Ohio University; Original Work Grant of Ohio University; and Nanoscale \& Quantum Phenomena Institute (NQPI) fellowship of Ohio University to D.K. This work was supported by a grant from the Ohio University Baker Fund to A.M.S. The funder had no role in the experimental design, data analysis, decision to publish, or preparation of the manuscript.

\section{Authors' contributions}

D.K. conducted the experiments. M.A.H. directed the monosaccharide composition analysis and proofread the manuscript. M.R.S. helped with extensive phenotypic analysis of the mutants, specifically SEM and proofread the manuscript. A.M.S. and D.K. conceived the study and wrote the manuscript. All authors have read and approved the manuscript.

\section{Funding}

This work was supported by a grant from the Ohio University Baker Fund to A.M.S. and College of Arts and Sciences Graduate student Research Fund to D.K. The funder had no role in the experimental design, data analysis, decision to publish, or preparation of the manuscript.

\section{Availability of data and materials}

The datasets used and/or analyzed during the current study are available from the corresponding author upon reasonable request.

\section{Declarations}

\section{Ethics approval and consent to participate}

Not Applicable.

\section{Consent for publication}

Not Applicable.

\section{Competing interests}

The authors declare that they have no competing interests. Allan M. Showalter is a member of the editorial board (i.e., an Associate Editor) of this journal.

\section{Author details}

${ }^{1}$ Molecular and Cellular Biology Program, Ohio University, Athens, $\mathrm{OH}$ 45701-2979, USA. ${ }^{2}$ Department of Environmental \& Plant Biology, Ohio University, Athens, OH 45701-2979, USA. ${ }^{3}$ Department of Chemistry \& Biochemistry, Ohio University, Athens, OH 45701-2979, USA.

Received: 5 August 2021 Accepted: 24 November 2021 Published online: 13 December 2021

\section{References}

1. Hervé C, Siméon A, Jam M, Cassin A, Johnson $\mathrm{KL}$, Salmeán $\mathrm{AA}$, et al. Arabinogalactan proteins have deep roots in eukaryotes: identification of genes and epitopes in brown algae and their role in Fucus serratus embryo development. New Phytol. 2016;209:1428-41. https://doi.org/10. 1111/nph.13786.

2. Palacio-López K, Tinaz B, Holzinger A, Domozych DS. Arabinogalactan proteins and the extracellular matrix of Charophytes: a sticky business. Front. Plant Sci. 2019;10. https://doi.org/10.3389/fpls.2019.00447.

3. Schultz C, Johnson K, Currie G, Bacic A. The classical arabinogalactan protein gene family of Arabidopsis. Plant Cell. 2000;12:1751-68. https:// doi.org/10.2307/3871187.

4. Showalter AM, Keppler B, Lichtenberg J, Gu D, Welch LR. A bioinformatics approach to the identification, classification, and analysis of hydroxyproline-rich glycoproteins. Plant Physiol. 2010;153:485-513. https://doi.org/ 10.1104/pp.110.156554

5. Schultz CJ, Ferguson KL, Lahnstein J, Bacic A. Post-translational modifications of arabinogalactan-peptides of Arabidopsis thaliana endoplasmic reticulum and glycosylphosphatidylinositol-anchor signal cleavage sites and hydroxylation of proline. J Biol Chem. 2004;279:45503-11. https://doi. org/10.1074/jbc.M407594200.

6. Seifert GJ, Roberts K. The biology of arabinogalactan proteins. Ann Rev Plant Biol. 2007;58:137-61. https://doi.org/10.1146/annurev.arplant.58. 032806.103801

7. Majewska-Sawka A, Nothnagel EA. The multiple roles of arabinogalactan proteins in plant development. Plant Physiol. 2000;122:3-10. https://doi. org/10.1104/pp.122.1.3.

8. Willats WGT, Knox JP. A role for arabinogalactan-proteins in plant cell expansion: evidence from studies on the interaction of $\beta$-glucosyl Yariv reagent with seedlings of Arabidopsis thaliana. Plant J. 1996;9:919-25. https://doi.org/10.1046/j.1365-313X.1996.9060919.x.

9. Coimbra S, Costa M, Jones B, Mendes MA, Pereira LG. Pollen grain development is compromised in Arabidopsis agp6 agp 11 null mutants. J Exp Bot. 2009;60:3133-42. https://doi.org/10.1093/jxb/erp148.

10. Ellis M, Egelund J, Schultz CJ, Bacic A. Arabinogalactan-proteins: key regulators at the cell surface? Plant Physiol. 2010;153:403-19. https://doi. org/10.1104/pp.110.156000.

11. Zhang Y, Yang J, Showalter AM. AtAGP18, a lysine-rich arabinogalactan protein in Arabidopsis thaliana, functions in plant growth and development as a putative co-receptor for signal transduction. Plant Signal Behav. 2011;6:855-7. https://doi.org/10.4161/psb.6.6.15204.

12. Nguema-Ona E, Coimbra S, Vicre-Gibouin M, Mollet J-C, Driouich A. Arabinogalactan proteins in root and pollen-tube cells: distribution and functional aspects. Ann Bot. 2012;110:383-404. https://doi.org/10.1093/ $\mathrm{aob} / \mathrm{mcs} 143$.

13. Olmos E, García De La Garma J, Gomez-Jimenez MC, Fernandez-Garcia N. Arabinogalactan proteins are involved in salt-adaptation and vesicle trafficking in tobacco BY-2 cell cultures. Front Plant Sci. 2017;8. https:// doi.org/10.3389/fpls.2017.01092.

14. Kieliszewski MJ, O'Neill M, Leykam J, Orlando R. Tandem mass spectrometry and structural elucidation of glycopeptides from a hydroxyprolinerich plant cell wall glycoprotein indicate that contiguous hydroxyproline residues are the major sites of hydroxyproline O-arabinosylation. J Biol Chem. 1995;270:2541-9. https://doi.org/10.1074/jbc.270.6.2541.

15. Tan L, Qiu F, Lamport DTA, Kieliszewski MJ. Structure of a hydroxyproline (Hyp)-arabinogalactan polysaccharide from repetitive ala-Hyp expressed in transgenic Nicotiana tabacum. J Biol Chem. 2004;279:13156-65. https://doi.org/10.1074/jbc.M311864200.

16. Kieliszewski MJ, Kamyab A, Leykam JF, Lamport DTA. A histidine-rich extensin from Zea mays is an arabinogalactan protein. Plant Physiol. 1992;99:538-47.

17. Du H, Clarke AE, Bacic A. Arabinogalactan-proteins: a class of extracellular matrix proteoglycans involved in plant growth and development. Trends Cell Biol. 1996;6:411-4. https://doi.org/10.1016/S0962-8924(96)20036-4.

18. Nothnagel EA. Proteoglycans and related components in plant cells. International review of cytology: Elsevier; 1997. p. 195-291. https://doi. org/10.1016/S0074-7696(08)62118-X.

19. Qu Y, Egelund J, Gilson PR, Houghton F, Gleeson PA, Schultz CJ, et al. Identification of a novel group of putative Arabidopsis thaliana $\beta$-(1,3)galactosyltransferases. Plant Mol Biol. 2008;68:43-59. https://doi.org/10. 1007/s11103-008-9351-3.

20. Suzuki T, Narciso JO, Zeng W, van de Meene A, Yasutomi M, Takemura $S$, et al. KNS4/UPEX1: a type II arabinogalactan $\beta$ - (1,3)-galactosyltransferase required for pollen exine development. Plant Physiol. 2017;173:183-205. https://doi.org/10.1104/pp.16.01385. 
21. Geshi N, Johansen JN, Dilokpimol A, Rolland A, Belcram K, Verger S, et al. A galactosyltransferase acting on arabinogalactan protein glycans is essential for embryo development in Arabidopsis. Plant J. 2013;76:12837. https://doi.org/10.1111/tpj.12281.

22. Dilokpimol A, Poulsen CP, Vereb G, Kaneko S, Schulz A, Geshi N. Galactosyltransferases from Arabidopsis thaliana in the biosynthesis of type II arabinogalactan: molecular interaction enhances enzyme activity. BMC Plant Biol. 2014;14:90.

23. Knoch E, Dilokpimol A, Tryfona T, Poulsen CP, Xiong G, Harholt J, et al. A $\beta$-glucuronosyltransferase from Arabidopsis thaliana involved in biosynthesis of type II arabinogalactan has a role in cell elongation during seedling growth. Plant J. 2013;76:1016-29. https://doi.org/10.1111/tpj. 12353.

24. Dilokpimol A, Geshi N. Arabidopsis thaliana glucuronosyltransferase in family GT14. Plant Signal Behav. 2014;9:e28891. https://doi.org/10.4161/ psb.28891.

25. Wu Y, Williams M, Bernard S, Driouich A, Showalter AM, Faik A. Functional identification of two nonredundant Arabidopsis a $(1,2)$ fucosyltransferases specific to arabinogalactan proteins. J Biol Chem. 2010;285:13638-45. https://doi.org/10.1074/jbc.M110.102715.

26. Liang Y, Basu D, Pattathil S, Xu W, Venetos A, Martin SL, et al. Biochemical and physiological characterization of fut 4 and fut6 mutants defective in arabinogalactan-protein fucosylation in Arabidopsis. J Exp Bot. 2013;64:5537-51. https://doi.org/10.1093/jxb/ert321.

27. Tryfona T, Theys TE, Wagner T, Stott K, Keegstra K, Dupree P. Characterisation of FUT4 and FUT6 $\mathrm{a}-(1 \rightarrow 2)$-fucosyltransferases reveals that absence of root arabinogalactan fucosylation increases Arabidopsis root growth salt sensitivity. Muday G, editor. PLoS One. 2014;9:e93291. https://doi.org/10.1371/journal.pone.0093291.

28. Gille S, Sharma V, Baidoo EEK, Keasling JD, Scheller HV, Pauly M. Arabinosylation of a yariv-precipitable cell wall polymer impacts plant growth as exemplified by the Arabidopsis glycosyltransferase mutant ray1. Mol Plant. 2013;6:1369-72. https://doi.org/10.1093/mp/sst029.

29. Narciso JO, Zeng W, Ford K, Lampugnani ER, Humphries J, Austarheim I, et al. Biochemical and functional characterization of GALT8, an Arabidopsis GT31 $\beta$-(1,3)-galactosyltransferase that influences seedling development. Front Plant Sci. 2021;12:678564. https://doi.org/10.3389/ fpls.2021.678564.

30. Basu D, Wang W, Ma S, DeBrosse T, Poirier E, Emch K, et al. Two hydroxyproline galactosyltransferases, GALT5 and GALT2, function in arabinogalactan-protein glycosylation, growth and development in Arabidopsis. PLOS ONE. 2015;10:e0125624. https://doi.org/10.1371/ journal.pone.0125624.

31. Basu D, Tian L, Wang W, Bobbs S, Herock H, Travers A, et al. A small multigene hydroxyproline-O-galactosyltransferase family functions in arabinogalactan-protein glycosylation, growth and development in Arabidopsis. BMC Plant Biol. 2015;15. https://doi.org/10.1186/ s12870-015-0670-7.

32. Ogawa-Ohnishi M, Matsubayashi Y. Identification of three potent hydroxyproline $\mathrm{O}$-galactosyltransferases in Arabidopsis. Plant J. 2015;81:736-46. https://doi.org/10.1111/tpj.12764.

33. Showalter AM, Basu D. Glycosylation of arabinogalactan-proteins essential for development in Arabidopsis. Commun Integr Biol. 2016;9:e1177687. https://doi.org/10.1080/19420889.2016.1177687.

34. Basu D, Tian L, Debrosse T, Poirier E, Emch K, Herock H, et al. Glycosylation of a fasciclin-like arabinogalactan-protein (SOS5) mediates root growth and seed mucilage adherence via a cell wall receptor-like kinase (FEI1/FEI2) pathway in Arabidopsis. PLoS One. 2016;11. https:// doi.org/10.1371/journal.pone.0145092.

35. Zhang Y, Held MA, Kaur D, Showalter AM. CRISPR-Cas 9 multiplex genome editing of the hydroxyproline-O-galactosyltransferase gene family alters arabinogalactan-protein glycosylation and function in Arabidopsis. BMC Plant Biol. 2021;21:16. https://doi.org/10.1186/ s12870-020-02791-9.

36. Le BH, Cheng C, Bui AQ, Wagmaister JA, Henry KF, Pelletier J, et al. Global analysis of gene activity during Arabidopsis seed development and identification of seed-specific transcription factors. Proc Natl Acad Sci U S A. 2010;107:8063-70. https://doi.org/10.1073/pnas.1003530107.

37. Nordborg M, Borevitz JO, Bergelson J, Berry CC, Chory J, Hagenblad J, et al. The extent of linkage disequilibrium in Arabidopsis thaliana. Nat Genet. 2002;30:190-3. https://doi.org/10.1038/ng813.
38. Kitazawa K, Tryfona T, Yoshimi Y, Hayashi Y, Kawauchi S, Antonov L, et al. $\beta$-Galactosyl yariv reagent binds to the $\beta-1,3$-galactan of arabinogalactan proteins. Plant Physiol. 2013;161:1117-26. https://doi.org/10. 1104/pp.112.211722.

39. Ding $L$, Zhu J-K. A role for arabinogalactan-proteins in root epidermal cell expansion. Planta. 1997;203:289-94. https://doi.org/10.1007/s0042 50050194.

40. Harpaz-Saad S, McFarlane HE, Xu S, Divi UK, Forward B, Western TL, et al. Cellulose synthesis via the FEI2 RLK/SOS5 pathway and CELLULOSE SYNTHASE 5 is required for the structure of seed coat mucilage in Arabidopsis. The Plant J. 2011;68:941-53. https://doi.org/10.1111/j. 1365-313X.2011.04760.X

41. Strasser R, Bondili JS, Vavra U, Schoberer J, Svoboda B, Glössl J, et al. A unique $\beta 1,3$-galactosyltransferase is indispensable for the biosynthesis of $\mathrm{N}$-glycans containing Lewis a structures in Arabidopsis thaliana. Plant Cell. 2007;19:2278-92. https://doi.org/10.1105/tpc.107.052985.

42. Lamport DTA, Kieliszewski MJ, Showalter AM. Salt stress upregulates periplasmic arabinogalactan proteins: using salt stress to analyse AGP function. New Phytol. 2006;169:479-92. https://doi.org/10.1111/j.14698137.2005.01591.x

43. Lamport DTA, Varnai P, Seal CE. Back to the future with the AGP-Ca2+ flux capacitor. Ann Bot. 2014;1 14:1069-85. https://doi.org/10.1093/ aob/mcu161.

44. Duan J, Zheng Y, Dong Q, Fang J. Structural analysis of a pectic polysaccharide from the leaves of Diospyros kaki. Phytochemistry. 2004;65:609-15.

45. Tan L, Eberhard S, Pattathil S, Warder C, Glushka J, Yuan C, et al. An Arabidopsis cell wall proteoglycan consists of pectin and Arabinoxylan covalently linked to an arabinogalactan protein. Plant Cell. 2013;25:270-87.

46. Tan L, Showalter AM, Egelund J, Hernandez-Sanchez A, Doblin MS, Bacic A. Arabinogalactan-proteins and the research challenges for these enigmatic plant cell surface proteoglycans. Front Plant Sci. 2012;3. https://doi. org/10.3389/fpls.2012.00140.

47. Lopez-Hernandez F, Tryfona T, Rizza A, Yu XL, Harris MOB, Webb AAR, et al. Calcium binding by arabinogalactan polysaccharides is important for normal plant development. Plant Cell. 2020;32:3346-69. https://doi.org/ 10.1105/tpc.20.00027.

48. Gaspar Y, Johnson KL, McKenna JA, Bacic A, Schultz CJ. The complex structures of arabinogalactan-proteins and the journey towards understanding function. Plant Mol Biol. 2001;47:161-76.

49. Johnson KL, Jones BJ, Bacic A, Schultz CJ. The Fasciclin-like arabinogalactan proteins of arabidopsis. A multigene family of putative cell adhesion molecules. Plant Physiol. 2003;133:1911-25. https://doi.org/10.1104/ pp.103.031237.

50. Yang J, Sardar HS, McGovern KR, Zhang Y, Showalter AM. A lysine-rich arabinogalactan protein in Arabidopsis is essential for plant growth and development, including cell division and expansion. Plant J. 2007:49:62940. https://doi.org/10.1111/j.1365-313X.2006.02985.x.

51. Velasquez SM, Ricardi MM, Dorosz JG, Fernandez PV, Nadra AD, Pol-Fachin $L$, et al. O-glycosylated cell wall proteins are essential in root hair growth. Science. 2011;332:1401-3. https://doi.org/10.1126/science.1206657.

52. Velasquez SM, Ricardi MM, Poulsen CP, Oikawa A, Dilokpimol A, Halim $A$, et al. Complex regulation of prolyl-4-hydroxylases impacts root hair expansion. Mol Plant. 2015;8:734-46. https://doi.org/10.1016/j.molp.2014. 11.017

53. Hengel AJV, Roberts K. AtAGP30, an arabinogalactan-protein in the cell walls of the primary root, plays a role in root regeneration and seed germination. Plant J. 2003;36:256-70.

54. Liu C, Mehdy MC. A nonclassical arabinogalactan protein gene highly expressed in vascular tissues, AGP31, is transcriptionally repressed by methyl Jasmonic acid in Arabidopsis. Plant Physiol. 2007;145:863-74.

55. MacMillan CP, Mansfield SD, Stachurski ZH, Evans R, Southerton SG. Fasciclin-like arabinogalactan proteins: specialization for stem biomechanics and cell wall architecture in Arabidopsis and Eucalyptus. The Plant J. 2010;62:689-703. https://doi.org/10.1111/j.1365-313X.2010.04181.x.

56. Liu E, MacMillan CP, Shafee T, Ma Y, Ratcliffe J, van de Meene A, et al. Fasciclin-like arabinogalactan-protein 16 (FLA16) is required for stem development in Arabidopsis. Front Plant Sci. 2020;1 1. https://doi.org/10. 3389/fpls.2020.615392.

57. Liu S, Tang Y, Ruan N, Dang Z, Huang Y, Miao W, et al. The rice BZ1 locus is required for glycosylation of arabinogalactan proteins and galactolipid 
and plays a role in both mechanical strength and leaf color. Rice. 2020;13:41. https://doi.org/10.1186/s12284-020-00400-9.

58. Sardar HS, Yang J, Showalter AM. Molecular interactions of arabinogalactan proteins with cortical microtubules and F-actin in bright yellow-2 tobacco cultured cells. Plant Physiol. 2006;142:1469-79. https://doi.org/ 10.1104/pp.106.088716.

59. Nguema-Ona E, Bannigan A, Chevalier L, Baskin TI, Driouich A. Disruption of arabinogalactan proteins disorganizes cortical microtubules in the root of Arabidopsis thaliana. Plant J. 2007;52:240-51. https://doi.org/10.1111/j. 1365-313X.2007.03224.x.

60. Driouich A, Baskin TI. Intercourse between cell wall and cytoplasm exemplified by arabinogalactan proteins and cortical microtubules. Am J Bot. 2008;95:1491-7. https://doi.org/10.3732/ajb.0800277.

61. Goldberg RB, de Paiva G, Yadegari R. Plant embryogenesis: zygote to seed. Science. 1994;266:605-14.

62. Voiniciuc C, Zimmermann E, Schmidt MH-W, Günl M, Fu L, North HM, et al. Extensive natural variation in Arabidopsis seed mucilage structure. Front. Plant Sci. 2016;7. https://doi.org/10.3389/fpls.2016.00803.

63. Suzuki T, Masaoka K, Nishi M, Nakamura K, Ishiguro S. Identification of kaonashi mutants showing abnormal pollen exine structure in Arabidopsis thaliana. Plant Cell Physiol. 2008;49:1465-77. https://doi.org/10.1093/ pcp/pcn131.

64. Costa M, Nobre MS, Becker JD, Masiero S, Amorim MI, Pereira LG, et al. Expression-based and co-localization detection of arabinogalactan protein 6 and arabinogalactan protein 11 interactors in Arabidopsis pollen and pollen tubes. BMC Plant Biol. 2013;13:7. https://doi.org/10.1186/ 1471-2229-13-7.

65. Leszczuk A, Kozioł A, Szczuka E, Zdunek A. Analysis of AGP contribution to the dynamic assembly and mechanical properties of cell wall during pollen tube growth. Plant Sci. 2019;281:9-18. https://doi.org/10.1016/j. plantsci.2019.01.005.

66. Losada JM, Herrero M. Arabinogalactan-protein secretion is associated with the acquisition of stigmatic receptivity in the apple flower. Ann Bot. 2012;110:573-84. https://doi.org/10.1093/aob/mcs116.

67. Losada JM, Herrero M. Pollen tube access to the ovule is mediated by glycoprotein secretion on the obturator of apple (Malus $\times$ domestica Borkh). Ann Bot. 2017:mcw276. https://doi.org/10.1093/aob/mcw276.

68. Dresselhaus T, Coimbra S. Plant reproduction: AMOR enables males to respond to female signals. Curr Biol. 2016;26:R321-3. https://doi.org/10. 1016/j.cub.2016.03.019.

69. Jiao J, Mizukami AG, Sankaranarayanan S, Yamguchi J, Itami K, Higashiyama T. Structure-activity relation of AMOR sugar molecule that activates pollen-tubes for ovular guidance. Plant Physiol. 2017;173:354-63. https:// doi.org/10.1104/pp.16.01655.

70. Conn SJ, Hocking B, Dayod M, Xu B, Athman A, Henderson S, et al. Protocol: Optimising hydroponic growth systems for nutritional and physiological analysis of Arabidopsis thaliana and other plants. Plant Methods. 2013;9:4. https://doi.org/10.1186/1746-4811-9-4.

71. Lamport D. Preparation of arabinogalactan glycoproteins from plant tissue. Bio-Protocol. 2013;3. https://doi.org/10.21769/BioProtoc.918.

72. Øbro J, Harholt J, Scheller HV, Orfila C. Rhamnogalacturonan I in Solanum tuberosum tubers contains complex arabinogalactan structures. Phytochem. 2004;65:1429-38. https://doi.org/10.1016/j.phytochem.2004.05. 002.

73. Gindler EM, King JD. Rapid colorimetric determination of calcium in biologic fluids with methylthymol blue. Am J Clin Pathol. 1972;58:376-82. https://doi.org/10.1093/ajcp/58.5.376.

74. Zhang Y, Held MA, Showalter AM. Elucidating the roles of three $\beta$-glucuronosyltransferases (GLCATs) acting on arabinogalactan-proteins using a CRISPR-Cas9 multiplexing approach in Arabidopsis. BMC Plant Biol. 2020;20:221. https://doi.org/10.1186/s12870-020-02420-5.

75. Chen R, Jiang H, Li L, Zhai Q, Qi L, Zhou W, et al. The Arabidopsis mediator subunit med25 differentially regulates jasmonate and abscisic acid signaling through interacting with the MYC2 and $\mathrm{AB} 15$ transcription factors. Plant Cell. 2012;24:2898-916. https://doi.org/10.1105/tpc.112.098277.

76. Zhai Q, Zhang X, Wu F, Feng H, Deng L, Xu L, et al. Transcriptional mechanism of jasmonate receptor COI1-mediated delay of flowering time in Arabidopsis. Plant Cell. 2015;27:2814-28. https://doi.org/10.1105/tpc.15. 00619.

77. Rodriguez-Enriquez MJ, Mehdi S, Dickinson HG, Grant-Downton RT. A novel method for efficient in vitro germination and tube growth of
Arabidopsis thaliana pollen. New Phytol. 2013;197:668-79. https://doi.org/ 10.1111/nph.12037.

78. MacAlister CA, Ortiz-Ramírez C, Becker JD, Feijó JA, Lippman ZB. Hydroxyproline $\mathrm{O}$-arabinosyltransferase mutants oppositely alter tip growth in Arabidopsis thaliana and Physcomitrella patens. Plant J. 2016;85:193-208. https://doi.org/10.1111/tpj.13079.

\section{Publisher's Note}

Springer Nature remains neutral with regard to jurisdictional claims in published maps and institutional affiliations.
Ready to submit your research? Choose BMC and benefit from:

- fast, convenient online submission

- thorough peer review by experienced researchers in your field

- rapid publication on acceptance

- support for research data, including large and complex data types

- gold Open Access which fosters wider collaboration and increased citations

- maximum visibility for your research: over 100M website views per year

At BMC, research is always in progress.

Learn more biomedcentral.com/submissions 